\title{
Dominios y fronteras en la Amazonía colonial. EI Tratado de San Ildefonso (1777-1790)
}

\author{
Simei Maria de Souza Torres \\ Universidad Federal de Amazonas (Brasil) \\ smstorres@uol.com.br
}

\begin{abstract}
Resumen
Las demarcaciones de fronteras en el norte de la América portuguesa, espacio hoy conocido como Amazonía, ha recibido un tratamiento poco significativo por parte de la historiografía brasileña. Reuniendo y analizando un conjunto diversificado de fuentes (diarios de viaje, mapas y documentos oficiales) de la segunda mitad del siglo XVIII, el artículo busca construir una interpretación del proceso histórico de las demarcaciones de límites y fronteras originadas en el Tratado Preliminar de Límites de San Ildefonso.

Palabras clave: FRONTERAS, BRASIL COLONIAL, AMÉRICA ESPAÑOLA, AMAZONÍA, TRATADO DE SAN ILDEFONSO (1777-1790).
\end{abstract}

\begin{abstract}
The drawing of the national border in the north of Portuguese America, today known as the Amazon, has not received significant enough of a treatment by Brazilian historiography. Through gathering and analyzing materials from a wide variety of sources (travel diaries, maps and official documents) dating from the second half of the eighteenth century, this article will look to construct an interpretation of the historical process of the drawing of the boundaries and borders created in the Prelimary Treaty for the Borders of San Ildefonso (el Tratado Preliminar de Limites de San Ildefonso).
\end{abstract}

Key words: FRONTIERS, BRAZIL COLONIAL, SPANISH AMERICA, AMAZONIA, TEATRY OF SAN ILDELFONSO (1777-1790). 
¡Colocad dos hombres en el Universo, decía el eminente autor del Espíritu de las Leyes, y en breve tiempo se hallarán en lucha por sus respectivas fronteras! ${ }^{1}$

Determinar la posesión de dominios se volvió un problema cuando Portugal y España iniciaron el proceso de expansión ultramarina y la ocupación del continente americano. El Tratado de Tordesillas, firmado en 1494, sirvió significativamente para resolver esta cuestión, puesto que fijaba los límites de acción y autoridad de las dos Coronas en el Atlántico. Con este reparto la Amazonía le correspondió a la Corona española.

A mediados del siglo XVIII los acuerdos del Tratado de Tordesillas se tornaron obsoletos. La expansión y ocupación de nuevos territorios por Portugal y España, tanto en América como en Asia, hacía mucho tiempo que no obedecían a los límites establecidos. Con la intención de resolver la misma cuestión, la posesión de dominio, negociaron el Tratado de Límites que, firmado en Madrid el 13 de enero de 1750, determinaba el cambio de Sete Povos, que pertenecería a Portugal, por Sacramento, que le correspondería a España, y utilizaba los principios del uti possidetis (la tierra pertenece a quien la ocupa) y los límites naturales (ríos y canales) para demarcar las demás fronteras, garantizando así el dominio de Portugal sobre gran parte de la cuenca amazónica y a España el total control de la cuenca del Plata.

Instrumento de difícil aplicación en el sur e inoperante en el norte, el Tratado de Madrid no obtuvo éxito, a pesar de los esfuerzos y del grupo de especialistas (militares, ingenieros, cartógrafos y astrónomos) que componían las comisiones destinadas al trabajo de las demarcaciones. Muchos fueron los obstáculos enfrentados. Al sur, los intereses en el intercambio con el Plata y la Guerra Guaraní contribuyeron al fracaso de las intenciones acordadas. Al norte las "partidas de límites" ni siquiera se vieron, y quedaron los portugueses esperando durante años a los españoles, que intentaban superar sus dificultades administrativas, sus enfrentamientos con los indios en el Orinoco y las provocaciones de los jesuitas, sin lograr llegar a la aldea de Mariuá, escogida como sede de la conferencias².

Como si no bastase esta incompatibilidad y las innumerables dificultades y contratiempos que impidieron la realización de lo dispuesto en el Tratado, la participación de las dos Coronas en la Guerra de los Siete Años también ofreció una vital contribución para su anulación. El Tratado

\footnotetext{
1 "Límites de Brasil (1493 a 1851)", Revista do Iinstituto Histórico e Geográfico Brasileiro, tomo 30, parte segunda (s.f), 25.

${ }^{2}$ Durante dos años Francisco Xavier de Mendonça Furtado, capitán general del Estado de Grão-Pará e Maranhão y plenipotenciario de la comisión de demarcaciones de límites del norte, lanzó a su equipo de geógrafos y astrónomos en una actividad febril de inventario geográfico y cartográfico, reuniendo informaciones que serían valiosas para una futura y definitiva demarcación de las fronteras en la región. Estableció el fuerte de Marabitanas, el fuerte de São Joaquim e instaló la capitanía de São José do Javari. Cf. Arthur C. Reis Ferreira, Limites e Demarcações na Amazônia Brasileira-A Fronteira com as Colônias Espanholas, Coleção Lendo o Pará, no. 15 (Belém: SECULT, 1993), 2: 41-94 y José Oscar Beozzo, Leis e Regimentos das Missões: política indigenista no Brasil (São Paulo: Loyola, 1983), 54.
} 
del Pardo, firmado el 12 de febrero de 1761, fue el instrumento utilizado para cancelar y anular definitivamente el de Madrid, como si nunca hubiera existido o hubiera sido ejecutado.

De esta forma, América volvía a su condición anterior, o sea, de fronteras indeterminadas. Tres artículos fueron suficientes para descartar once años de formación territorial y de una política de paz y amistad, a pesar de los enfrentamientos en el sur, en Mato Grosso y también en la Amazonía. La ojeriza que separaba a portugueses y españoles en Europa quedaba aún más fortalecida y se trasladaba ahora al continente americano ${ }^{3}$.

Solamente con la muerte del rey José I y la caída del Marqués de Pombal (la "Viradeira") es que tal situación se revertiría. Las transformaciones ocurridas en los negocios políticos del reino portugués revelaban la debilidad ante el vecino, llevando a María I, al asumir el trono, a observar la necesidad de restablecer las relaciones con la Corte española. El fin de las desavenencias en el Nuevo Mundo servía bien a este propósito y después de veintisiete años de tentativas de delimitar el sur de América, principalmente los límites de Brasil, se celebró un Tratado Preliminar de Límites, negociado para Portugal por Don Francisco Inocencio de Souza Coutinho y, por España, por Don José Menino y Redondo, Conde de Florida Blanca.

Firmado el 1 de octubre de 1777 en San Ildefonso, con 25 artículos, rehabilitaba, en líneas generales, el de 1750. Las alteraciones contenidas en los artículos significaban para Portugal una gran pérdida de territorio en el sur, ya que tanto Sacramento como Sete Povos das Missões deberían entregarse a España ${ }^{4}$. En el norte se mantenía el artículo IX del tratado anterior que cubría la región entre los ríos Japurá y Negro, pues en el artículo XX se mencionaba la ejecución del tratado en las dos orillas del río Marañón "o de Amazonas".

Las demarcaciones limítrofes resultantes de este tratado también tuvieron pocos efectos. Después de dos años de trabajo las desavenencias entre las dos partes volvieron imposible su continuación, pero esta vez los comisarios de Portugal y España se encontraron sucesivas veces durante varios años a lo largo de toda la extensión fronteriza, enfrentando situaciones más y más complejas, y reuniendo una vasta documentación entre cartas, descripciones, informes, diarios, memoriales y un enorme acervo cartográfico.

En la historiografía nacional y regional las demarcaciones de límites de las fronteras brasileñas, sus temas y acontecimientos, merecieron un rico, elaborado y variado abordaje, especialmente en relación con el Tratado de Madrid y, principalmente, en lo que respecta al sur del país. Por el contrario, el Tratado de San Ildefonso, sobre todo en los aspectos concernientes al norte, sigue siendo poco analizado. Las investigaciones se han limitado a trazar un panorama general o a dar algunos destellos de información.

\footnotetext{
${ }^{3}$ Reis, Limites, 110 y 111.

${ }^{4}$ Aimberê Freitas, Fronteira Brasil/Venezuela: Encontros e Desencontros (São Paulo: Corprint Gráfica e Editora, 1998), 111.
} 
Francisco Adolpho Varnhagem comenta las condiciones en que fue firmado el tratado y la importancia de los trabajos efectuados a partir de 1777, resaltando la sumisión del indio Mura como el principal éxito obtenido en ese periodo ${ }^{5}$. Arthur Cezar Ferreira Reis ofrece en su obra, que alcanza casi cuatro siglos de historia del Amazonas ${ }^{6}$, el máximo de informaciones sobre el tratado y los acontecimientos del periodo de demarcación, realizando un trabajo semejante al de Lourenço da Silva Araújo e Amazonas?.

A partir de estas consideraciones y de la afirmación de Varnhagem, quien sostiene que lo que se hizo después de 1777 es de gran interés para la historia de la demarcación de fronteras ${ }^{8}$, el objetivo de este artículo es rescatar dicha historia en la Amazonía, durante la vigencia del Tratado Preliminar de Límites de San Ildefonso (1777-1790). Reuniendo y reconstituyendo los datos diseminados en la muy escasa historiografía nacional y regional, asociándolos con las fuentes primarias, especialmente la documentación del Archivo Histórico Ultramarino (AHU) y del Archivo Público del Estado de Pará (APEP), pertenecientes al acervo del Museo Amazónico de la Universidad Federal de Amazonas, se compondrá un cuadro más amplio y único del periodo.

\section{San Ildefonso: límites e instrucciones}

El Tratado Preliminar de Límites de San Ildefonso determinaba en los artículos III al XIV las fronteras que separarían los dominios de Portugal y España en el sur de América. Con este objeto deseaba extinguir las discordias seculares entre las dos Coronas y sus vasallos, celebrando una paz perpetua. En 1778 tuvo como apéndice el Tratado de la Amistad, Garantía y Comercio, el cual estipulaba que en caso de guerra con otra nación extranjera u quien quedase en paz sería neutral y, si fuese necesario, daría auxilio y no ofrecería asilo al enemigo. De esta forma, quedaba implícito que además de delimitar los territorios, uno de los objetivos de este tratado era el de proteger sus posesiones de invasiones.

En la Amazonía, los límites seguirían por el río Madeira hasta un punto situado a igual distancia del río Marañón/Amazonas y de la desembocadura del río Mamoré; a partir de allí por una línea este-oeste hasta la orilla derecha del río Javarí, siguiendo por su cauce hasta desaguar en el río Marañón/Amazonas y prosiguiendo hasta encontrar la desembocadura más occidental del río Japurá; subiendo por él hasta el punto en que quedarían cubiertos los asentamientos portugueses de las orillas del Japurá y Negro, como también la comunicación o canal que usaron los portugueses entre estos ríos desde 1750. La frontera continuaría además por el Negro hasta el Orinoco, llegando a la cordillera por los afluentes y lagos que fueran acordados.

\footnotetext{
${ }^{5}$ Francisco A. Varnhagem, História Geral do Brasil: antes de sua aeparação e independência de Portugal, tomos 3 y 4, 10a. ed. (São Paulo: EDUSP, 1981), 267-276.

${ }^{6}$ Arthur C. Ferreira Reis, História do Amazonas, 3a. ed. (Belo Horizonte: Itatiaia, 1998), 135-141.

${ }^{7}$ Lourenço da Silva Araújo e Amazonas, Dicionário Topographico, Histórico, Descriptivo da Comarca do AltoAmazonas (Recife: Typographia Commercial de Meira Henriques, 1852), 251-258.

${ }^{8}$ Varnhagem, História, 270.
} 
Con respecto a la navegación de los ríos, decidieron que sería común donde las dos orillas pertenecieran a ambas naciones y que se volvería privativa de aquella nación a la que correspondiesen sus dos orillas. Las islas existentes en los ríos por donde pasase la línea divisoria serían del dominio al que estuviesen más próximas durante la estación seca; y si estuviesen situadas a igual distancia de ambas orillas serían neutrales, excepto si fuesen de gran extensión y aprovechamiento, siendo entonces divididas y formando la correspondiente línea de separación para determinar los límites ${ }^{9}$.

Después de establecer los confines entre dos Coronas, las Cortes resolvieron formar cuatro "divisiones" o "partidas" y repartirlas por la línea de la frontera para abreviar y facilitar las demarcaciones en los extensos dominios del interior de América ${ }^{10}$. La cuarta división fue destinada a demarcar los límites de una parte de los terrenos del norte descritos en los artículos XII del Tratado Preliminar y IX del Tratado de Límites de 1750:

[...] los cuales ambos se reducen a que la demarcación, debiendo comenzar por la boca más occidental del Río Japurá, y subir por el medio de este río hasta encontrar el alto de la Cordillera de Montes, que media entre el Río Orinoco y el de las Amazonas [...]; y que ella permanezca sirviendo de baliza, desde la cual permanezcan cubiertos y vedados los asentamientos portugueses de las márgenes del dicho Japurá y del Río Negro, como también la comunicación o canal de que se sirven entre estos dos ríos, de suerte que ni los españoles descendiendo se introduzcan en los dominios de Portugal, ni los portugueses subiendo pasen a los dominios de España ${ }^{11}$.

\footnotetext{
${ }^{9}$ Este párrafo y el anterior corresponden a los artículos XI al XIV del Tratado de Límites de 1777.

${ }^{10} \mathrm{La} 1^{\mathrm{a}}$ división portuguesa pertenecería a la distribución del gobierno de Rio de Janeiro, la $2^{\mathrm{a}}$ al de São Paulo, la $3^{\mathrm{a}}$ al de Mato Grosso y la $4^{\mathrm{a}}$ al de Grão-Pará, "[...] cada uma delas composta de dois Comissários Principais, dois Engenheiros, dois Geógrafos, e dois Práticos do País, com a Comitiva proporcionada a este Número de Gente, e ao Serviço de que fosse incumbida". Cf. "Carta de D. Marí I al capitán general João Pereira Caldas. N. Señora de la Ayuda, 7 de enero de 1780", Museu Amazônico, Universidade Federal de Amazonas (en adelante MA), APEP, caja 17 , códice 1009 , docs. 15-20.

11 “[...] os quais ambos se reduzem, a que a Demarcação, devendo começar pela Boca mais Ocidental do Rio Japurá, e subir pelo meio deste Rio até encontrar o Alto da Cordilheira de Montes, que medeia entre o Rio Orenoco, e o das Amazonas, [...]; e que ela fique servindo de Baliza, da qual fiquem cobertos, e vedados os Estabelecimentos Portugueses das Margens do dito Japurá, e do Rio Negro, como também a Comunicação ou Canal de que se sirvam entre estes dois rios, de sorte que nem os Espanhóis descendo, se introduzam nos Domínios de Portugal, nem os Portugueses subindo, passem aos Domínios de España". "Carta del Ministro de los Negocios Ultramarinos, Martinho de Mello e Castro, al Capitán General João Pereira de Caldas. Nuestra Señora de la Ayuda, 8 de enero de 1780”, MA, APEP, caja 17, códice 1009, docs. 21-41.
} 


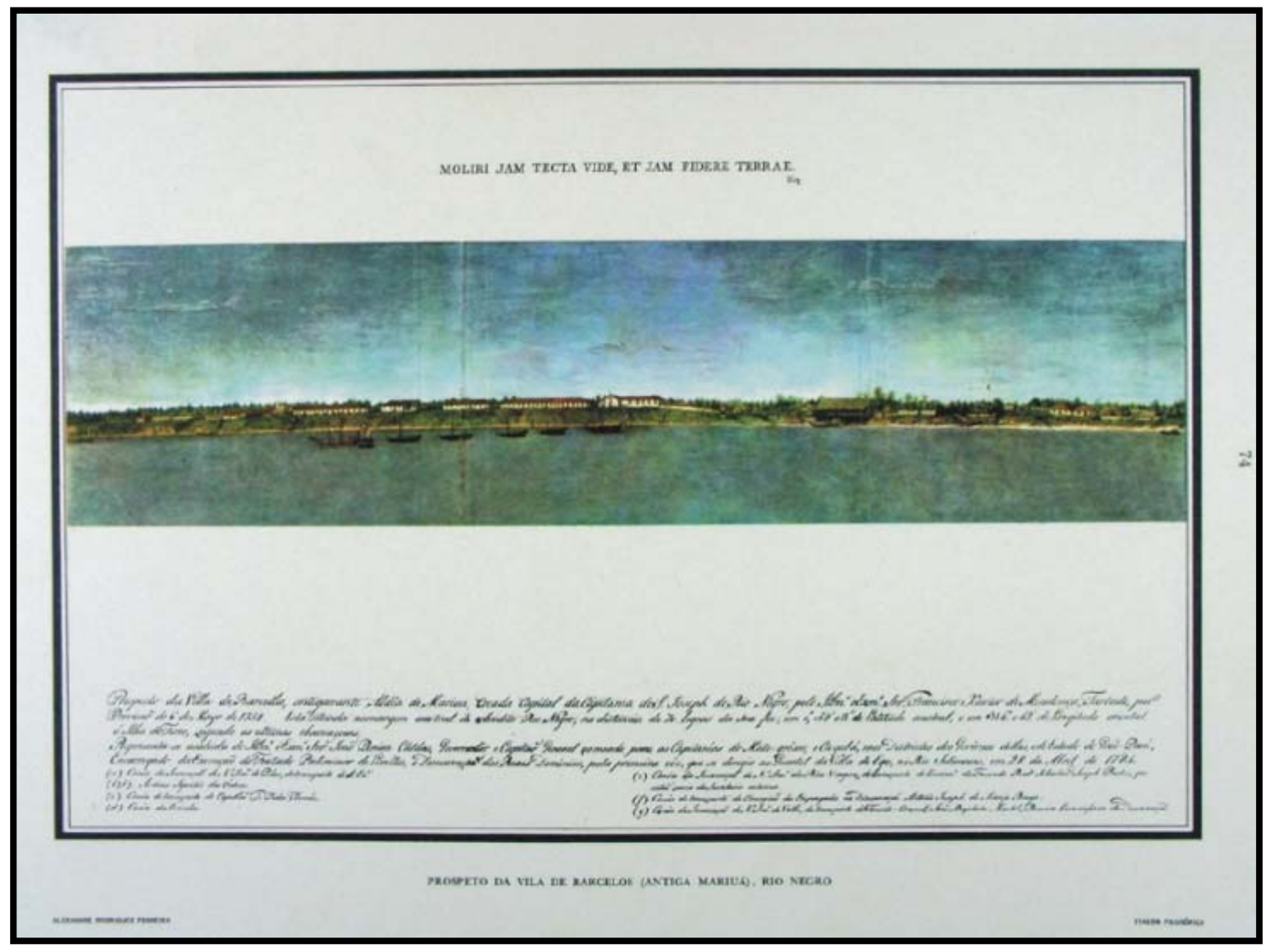

Fig. 1. Prospecto de Vila de Barcelos (antigüa Aldeia de Mariuá). Representa la salida del capitán general João Pereira Caldas, Plenipotenciario de la Comisión Portuguesa de Demarcación de Límites del Norte, en dirección a Vila de Ega, en el río Solimões, el 28 de abril de 1784. Mapa elaborado durante la expedición del naturalista Alexandre Rodrigues Ferreira (1783-1792). Tomado de: Livros Digitais, Série Amazoniana, Secretaria de Cultura do Estado do Amazonas (Manaus, 2002). 
En el artículo XV, las dos Coronas acordaban el nombramiento de comisarios para ejecutar los artículos del Tratado y determinar con exactitud los límites y puntos donde debería pasar la línea divisoria. Para la cuarta partida de demarcación de límites del norte fueron nombrados plenipotenciarios el capitán general João Pereira Caldas ${ }^{12}$, por Portugal, y, por España, D. Ramón García de León y Pizarro, nombrado poco tiempo después para el gobierno de Guayaquil, pasando a ocupar el cargo de primer comisario el capitán de infantería D. Francisco de Requeña y Herrera, gobernador político y militar de la provincia de Mainas ${ }^{13}$.

Nuevamente la villa de Barcelos fue escogida para servir de base a la comisión portuguesa de demarcación de límites que, a diferencia de lo sucedido en 1750, no necesitó contratar personal en otros países para componer su cuadro técnico; pues poseía gente preparada y en gran número para ejecutar las necesarias tareas de campo, ya que algunas personas que participaron en la demarcación anterior aún se encontraban en la colonia. El 17 de octubre de 1780, la antigua aldea de Mariuá recibiría al capitán general Pereira Caldas acompañado de una comitiva compuesta de quinientas dieciséis personas ${ }^{14}$.

A pesar de que los miembros de la tercera partida, ingenieros y astrónomos, partieron a Mato Grosso y algunos demarcadores, auxiliares y tropa destacada siguieron para Ega, Tabatinga y Borba, la mayor parte de la numerosa comitiva quedaría establecida en Barcelos. Para ello, Pereira Caldas ultimó la construcción de casas para residencia de los demarcadores, alojamientos para la tropa y servicios de oficina, reservando para sí un sitio próximo; estableció una fábrica de paños de algodón para el uniforme de los soldados, montó alfarerías y construyó puentes. Buscó dar vida y vigor a la villa que mostraba un estado de abandono y decadencia iniciado con la retirada de la comisión anterior.

En enero de 1781 el teniente coronel Theodozio Constantino de Chermont ${ }^{15}$, nombrado primer comisario de la cuarta partida portuguesa y sustituto legal de Pereira Caldas, se dirigió al pueblo de São Francisco Xavier da Tabatinga al encuentro de la comisión española, que bajaría por el

\footnotetext{
12 João Pereira Caldas fue ayudante de Francisco Xavier de Mendonça Furtado, y permaneció en la colonia después de la anulación del Tratado de Madrid. Fue gobernador de Piauí y de Grão-Pará. Nombrado gobernador de Mato Grosso, no llegó a asumir el cargo, siendo encargado interinamente de las Demarcaciones de Límites del Norte hasta la llegada de Joaquim de Mello e Póvoas, lo que no ocurrió. Se mantuvo en el servicio de las demarcaciones hasta 1788. Cf. Reis, História, 127.

${ }^{13}$ A pesar de que la historiografía afirma que D. Francisco Requeña no poseía capacidad para asumir el cargo, éste demostró gran astucia diplomática y política al lograr desviar a los portugueses de la demarcación del río Japurá y establecerse durante ocho años como señor absoluto en la Villa de Ega, periodo en que quedaron suspendidos los trabajos demarcatorios. Cf. Ibídem, 131-140.

${ }^{14}$ Alexandre Rodrigues Ferreira, Viagem Filosófica ao Rio Negro (Belém: MPEG, 1983), 420-429.

${ }^{15}$ Chermont embarcó para la Amazonía en 1760 a los 18 años, ascendido a capitán de infantería del Regimiento de la Guarnición de Belém de Grão-Pará. En 1767 fue nombrado sargento mayor del tercio de auxiliares de Macapá, sirviendo como capitán de infantería de $1^{\text {a }}$ línea. Ascendido a teniente general, en 1779 se volvió miembro de la comisión de demarcación en calidad de primer comisario. En 1791 delineó el primer mapa de la ciudad de Belém: Plan General de la Ciudad de Pará, y en 1792 pasó a servir como coronel del $2^{\circ}$ regimiento de infantería de $1^{\mathrm{a}}$ línea en Pará, finalizando su carrera militar como general de brigada reformado en 1811. Cf. Carlos E. Barata de Almeida y Antônio H. da Cunha Bueno, Dicionário das Famílias Brasileiras (São Paulo: Iberoamérica, s.f.), 731.
} 
río Marañón y no por el Negro, como pretendieron los demarcadores españoles del Tratado de Madrid.

En seguida, el 23 de febrero, partió de la villa de Ega la expedición destinada al reconocimiento del río Japurá, con el propósito de descubrir un camino fluvial o terrestre que comunicase los poblados del río Negro con el Japurá. Liderada por el segundo comisario Henrique João Wilckens ${ }^{16}$, junto con el matemático José Simões de Carvalho y el capitán ingeniero Pedro Alexandrino, acompañados de soldados, indios y prácticos; un total de ciento veintiocho personas en seis canoas. Después de catorce días de viaje llegaron a la desembocadura donde el río Auatyparaná entra en el Japurá, persuadiéndose el comisario Wilckens que ésta era la boca más occidental del río ${ }^{17}$.

Esos dos movimientos daban continuidad a los servicios de la demarcación y ejecutaban las primeras instrucciones reales recibidas por el plenipotenciario Pereira Caldas:

[...] hará partir inmediatamente para la población de São Francisco Xavier de Tabatinga, que queda junto a la boca del Javari, a la cuarta división, que se ha de juntar con la española en Pevas o en Tabatinga, en la forma que parezca más conveniente; y como la dicha división portuguesa tendrá que pasar necesariamente durante la ida por la boca más occidental del Río Japurá, será muy conveniente que parte de la misma división comandada por el segundo comisario permanezca luego en aquel sitio, para explorar el referido río, en cuanto el primer comisario con el resto de la misma división vayan a Tabatinga y junto a los españoles desciendan al Japurá $^{18}$.

\footnotetext{
${ }^{16}$ Wilckens llegó a Belém en 1753 con la comitiva del gobernador Mendonça Furtado, e integró en 1755 el equipo de demarcación de Mato Grosso como ayudante ingeniero. En 1764 recibió el grado de capitán de infantería con ejercicio de ingeniero. Asumió la dirección de las obras de la fortaleza y del hospital de Macapá en 1773. Fue promovido sargento mayor y segundo comisario para las demarcaciones del río Negro en 1777 . De este viaje al Japurá resultó un diario cuyas anotaciones fueron utilizadas en su poema épico "Muhuraida ou el triunfo da fé, 1785". Cf. Marta Rosa Amoroso y Nádia Fárage, Relatos da Fronteira Amazônica no Século XVIII: Alexandre Rodrigues Ferreira e Henrique João Wilckens (São Paulo: NHII; USP; FAPESP, 1994), 13-15.

17 "Carta del Ministro de los Negocios Ultramarinos, Martinho de Mello e Castro, al Capitán General João Pereira Caldas. Mafra, 29 de agosto de 1783”, MA, APEP, caja 17, códice 1009, docs 71-116.

18 “[...] fará partir imediatamente para a Povoação de São Francisco Xavier de Tabatinga, que fica junto da Boca do Javari, a Quarta Divisão, que se há de juntar com a Espanhola em Pevas, ou em Tabatinga, na forma que parecer mais conveniente; e como a dita Divisão Portuguesa há de necessariamente passar na ida pela Boca mais Ocidental do Río Japurá, será muito conveniente, que parte da mesma Divisão Comandada pelo segundo Comissário, fique logo naquele Sítio, para explorar o referido Rio enquanto o Primeiro Comissário com o resto da mesma Divisão passa a Tabatinga, e unido com Espanhóis descem ao Japurá". "Carta del Ministro de los Negocios Ultramarinos, Martinho de Mello e Castro, al Capitán General João Pereira Caldas. Nuestra Señora de la Ayuda, 8 de enero de 1780”, MA, APEP, caja 17, códice 1009, docs 21-41.
} 


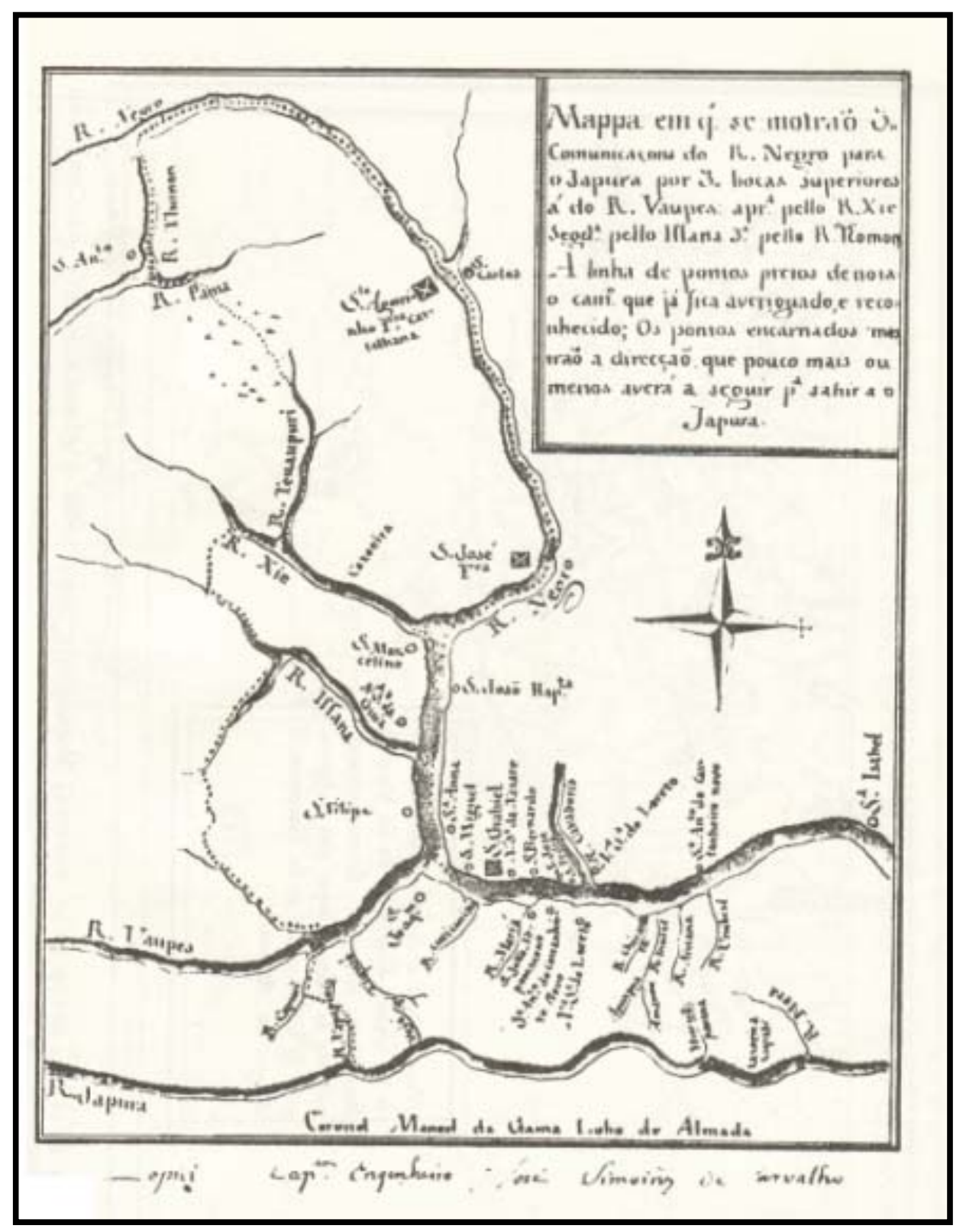

Fig. 2. Mapa del río Negro, afluentes y poblaciones portuguesas. Elaborado en 1784 por el capitán ingeniero José Simões de Carvalho, miembro de la Comisión de Demarcación de Límites del Norte. Tomado de: Boletim de CEDEAM, $\mathrm{n}^{\circ} 6$ (Manaus: Universidade do Amazonas, 1985). 
Por otro lado, la Corte madrileña también envió a su comisión destinada a las demarcaciones, formada por trescientas personas, que se diferenciaba mucho de la comisión portuguesa, tanto en número como en la composición de su cuerpo técnico, puesto que traía solamente dos comisarios: el primer comisario Requeña, ejerciendo también el cargo de ingeniero, y el capitán de milicias D. Felipe de Arrechua y Sarmiento, nombrado segundo comisario; un astrónomo, D. Apolinario Días de la Fuente (que se retiró poco después de la comisión por insuficiencia de conocimientos técnicos, dejando esta función para Requeña); un cirujano, el Doctor Manuel de Vera; un capellán, Mariano Bravo; un secretario, D. Gaspar Santisteban; un ayudante, D. Juan Salinas; el teniente D. Juan Manuel Benítez, comandante de la tropa, proveedor y tesorero de la Hacienda Real, y el sargento mayor D. Joaquín Fernández del Busto.

Desde su partida de Quito, en enero de 1780, la comisión española enfrentó serias dificultades, ya que los instrumentos necesarios para la demarcación como agujas, barómetro, teodolito, relojes y otros, solamente serían recibidos por el primer comisario español en 1782, e incluso el mapa destinado a los trabajos de demarcación fue extraviado ${ }^{19}$.

\section{Una historia de la demarcación}

A pesar de todas las dificultades la historia no se repitió. Las comisiones portuguesa y española se encontraron en São Francisco Xavier de Tabatinga en marzo de 1781. Con la reunión surgieron las primeras desavenencias. Justo al inicio, Requeña, con poca habilidad política y diplomática, resolvió ocupar el río Solimões hasta el Japurá y exigió del comandante de Tabatinga y de la junta gobernadora de la capitanía la entrega de la frontera y de aquella parte del territorio. Además de esto pretendió que fuese creada una comisión separada para las demarcaciones entre São José de Marabitanas y los puestos españoles en Cassiquiari.

El primer comisario español parecía no saber que era imposible atender sus deseos, o que tal vez fuera más conveniente así. La verdadera boca del Japurá, explicitada en el Tratado Preliminar de Límites como punto de partida para las demarcaciones, aún no era conocida $\mathrm{y}$, por lo tanto, no era posible determinar cuál territorio era español o portugués. Tampoco le correspondía a los demarcadores, por más poder que tuvieran, establecer nuevas comisiones, esto solamente era una prerrogativa de las dos Cortes. Pereira Caldas por esas razones juzgó infundados los deseos del comisario español que, curiosamente, tampoco insistió en el asunto; no hubo así consecuencias críticas para estas primeras dificultades ${ }^{20}$.

En 1781 D. Francisco Requeña, usando argumentos fundamentados en las noticias escritas por Charles-Marie de la Condamine ${ }^{21}$, consiguió persuadir al comisario portugués de entregar el

\footnotetext{
${ }^{19}$ Manuel Lucena Giraldo, Francisco de Requeña y otros: Ilustrados y bárbaros - Diario de la exploración de límites al Amazonas (1782) (Madrid: Alianza Editorial, 1991), 30-31; Reis, História, 136.

${ }^{20}$ Reis, História, 136-137.

${ }^{21}$ Condamine comandó la expedición francesa a la Amazonía en el primer cuarto del siglo XVIII, y produjo la obra Viagem pelo Amazonas, 1735-1745. Condamine demostraba una preocupación constante por la astronomía,
} 
poblado de São Francisco Xavier de Tabatinga, con su fuerte y demás edificaciones, inclusive el palacio de las demarcaciones, construido por la Compañía General de Comercio del Grão-Pará y Marañón para las conferencias que no ocurrieron en la primera tentativa de establecer las fronteras. Con el consentimiento de Chermont fue redactado el compromiso de entrega, que el sargento mayor Antonio Euzebio de Ribeiros se rehusó a firmar ${ }^{22}$, y por esta insubordinación permaneció preso durante nueve días, mientras afirmaba que sólo daría explicaciones de su negativa al plenipotenciario Pereira Caldas, que se encontraba en Barcelos.

La vehemente negativa de Ribeiros, la falta de acuerdo con los españoles sobre al precio de los edificios y la vacilación de Requeña en entregar los fuertes del río Negro (São Carlos y São Fellipe) a cambio del de Tabatinga, permitieron que el poblado de São Franciso Xavier de Tabatinga, la fortaleza y toda aquella zona de la frontera permaneciesen bajo el dominio de Portuga $^{23}$.

El sargento mayor Ribeiros parecía no sólo haber desconfiado de la astucia del español, sino que también percibía que la pérdida de Tabatinga sería perjudicial para Portugal. En su justificación a João Pereira Caldas intentó demostrar los "males" a los cuales Portugal estaría sujeto con los procedimientos de la demarcación:

El estado en que se halla esta demarcación; la forma que al presente existe; el rumbo que va tomando, conjeturo que para buscar innumerables males, a los cuales jamás Portugal dará satisfactorio remedio; todo son urgentes circunstancias que me motivan a decir a Vuestra Excelencia que en el caso de haberse tomado la resolución de entregar a Su Majestad Católica la población de S. Francisco Xavier de Tabatinga, por ningún modo se haga. Paso a demostrar las razones en que me baso.

El lugar que permite a los vasallos de Su Majestad Católica que transporten con facilidad municiones de boca y guerra, es aquel en que los excelentísimos señores generales (a los cuales Su Majestad Fidelísima tiene confiado el gobierno del Estado) deben tener mayor cuidado y vigilancia, en razón de que por semejante paso puede venirle al Estado una mayor ruina y perjuicio ${ }^{24}$.

recolectando datos importantes para la elaboración de mapas. Cf. Jonas Marçal de Queiroz y Mauro Cezar Coelho, Amazônia: Modernização e Conflito-séculos XVIII e XIX (Belém: UEPA/NAEA, 2001).

${ }^{22}$ Ribeiros sirvió como ayudante en la Academia Militar de Lisboa, transferido a Rio de Janeiro con el cargo de capitán de artillería. Fue empleado por el Marqués de Lavradio en diferentes comisiones, y recomendado a João Pereira Caldas por el ministro Martinho de Mello e Castro como "Oficial de préstimo [...] muito ativo, e trabalhador,

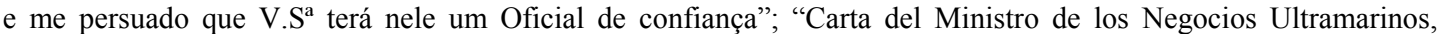
Martinho de Mello e Castro, al Capitán General João Pereira Caldas. Nuestra Señora de la Ayuda, 7 de enero de 1780", MA, APEP, caja 17, códice 1009, docs. 09-14.

${ }^{23}$ André Fernandes de Souza, "Notícias Geográficas da Capitania do Rio Negro no Grande Rio das Amazonas", Revista Trimensal de História e Geografia e Etnográfico do Brasil, no. 12 (1848), 449; Reis, História, 138.

24 "O estado em que se acha esta Demarcação: a Figura em que presentemente existe; o rumo que vai tomando, conjecturo que à buscar inumeráveis males, a que jamais Portugal, dará um sanável remédio, tudo são urgentes circunstâncias, que me motivam a dizer a V. Exa. que no caso de se ter tomado a resolução; de entregar a Sua 
Resueltas las desavenencias iniciales, portugueses y españoles dieron inicio a las primeras tareas demarcatorias. Efectuaron el reconocimiento del río Javarí, plantando un marco divisorio en su desembocadura el 5 de julio de 1781, y el 26 de septiembre colocaron otro delimitador en la desembocadura del canal del Auatyparaná que, de acuerdo con los portugueses, era la boca más occidental del Japurá. Con esta delimitación los portugueses se dejaban confinar en el Solimões, a pesar de que por un largo tiempo habian conquistado y tomado posesión de áreas muy próximas a los Andes ${ }^{25}$.

A finales de 1781, después de la ejecución de estos primeros trabajos, las comisiones se instalaron en Ega. La llegada de este contingente de personas alteraría mucho la cotidianidad de la pequeña villa y de sus habitantes. Además de la importancia de los puestos militares que ocupaban y del proyecto real en el que estaban empeñados, presentaban necesidades básicas y urgentes, siendo la primera de ellas la cuestión de los alojamientos. Entonces ocurrió en el Rio Solimões un episodio que sólo se vería nuevamente -guardadas las debidas proporcionespocos años después en Rio de Janeiro con la llegada del Príncipe Regente y la corte portuguesa a Brasil, el famoso "Ponha-se na rua".

Para apoyar a las partidas que trabajaban en las demarcaciones de los reales dominios, fueron "solicitadas" a los vecinos veinticuatro casas con sus respectivos muebles y pertenencias. Ni los indios se escaparon, puesto que diecisiete de estas casas les pertenecían. En 1784 los habitantes blancos que habían sido desalojados de sus viviendas y que precariamente se acomodaron en casas ajenas, se quejaron ante el teniente coronel João Baptista Mardel, primer comisario en la época, suplicando el reembolso de los arriendos de sus casas ${ }^{26}$.

Majestade Católica, a Povoação de S. Francisco Xavier de Tabatinga, por nenhum modo se faça. As razões em que me fundo passo a demonstrar.

Todo aquele lugar, que permite aos vassalos de Sua Majestade Católica, o transportarem com facilidade, munições de boca, e Guerra, este é aquele; em que os Exmos Srs. Generais [de quem sua majestade Fidelíssima tem confiado o Governo do Estado] deve ter o maior cuidado, e vigilância: a razão é porque por semelhante passo, pode vir ao Estado a maior ruína, e prejuízo". "Carta del Sargento Mayor Antônio Euzébio de Ribeiros al Capitán General João Pereira de Caldas. Ega, 30 de enero de 1782”, MA, APEP, caja 27, docs. 54-57.

${ }^{25}$ Araújo, Dicionário, 253.

26 "Carta y Relación de las Casas ocupadas por las dos partidas Portuguesa, y Española, en esta Villa de Ega del primer comisario Teniente Coronel João Baptista Mardel al Capitán General João Pereira Caldas. Ega, 19 de junio de 1784", MA, APEP, caja 18, docs. 50-55. 


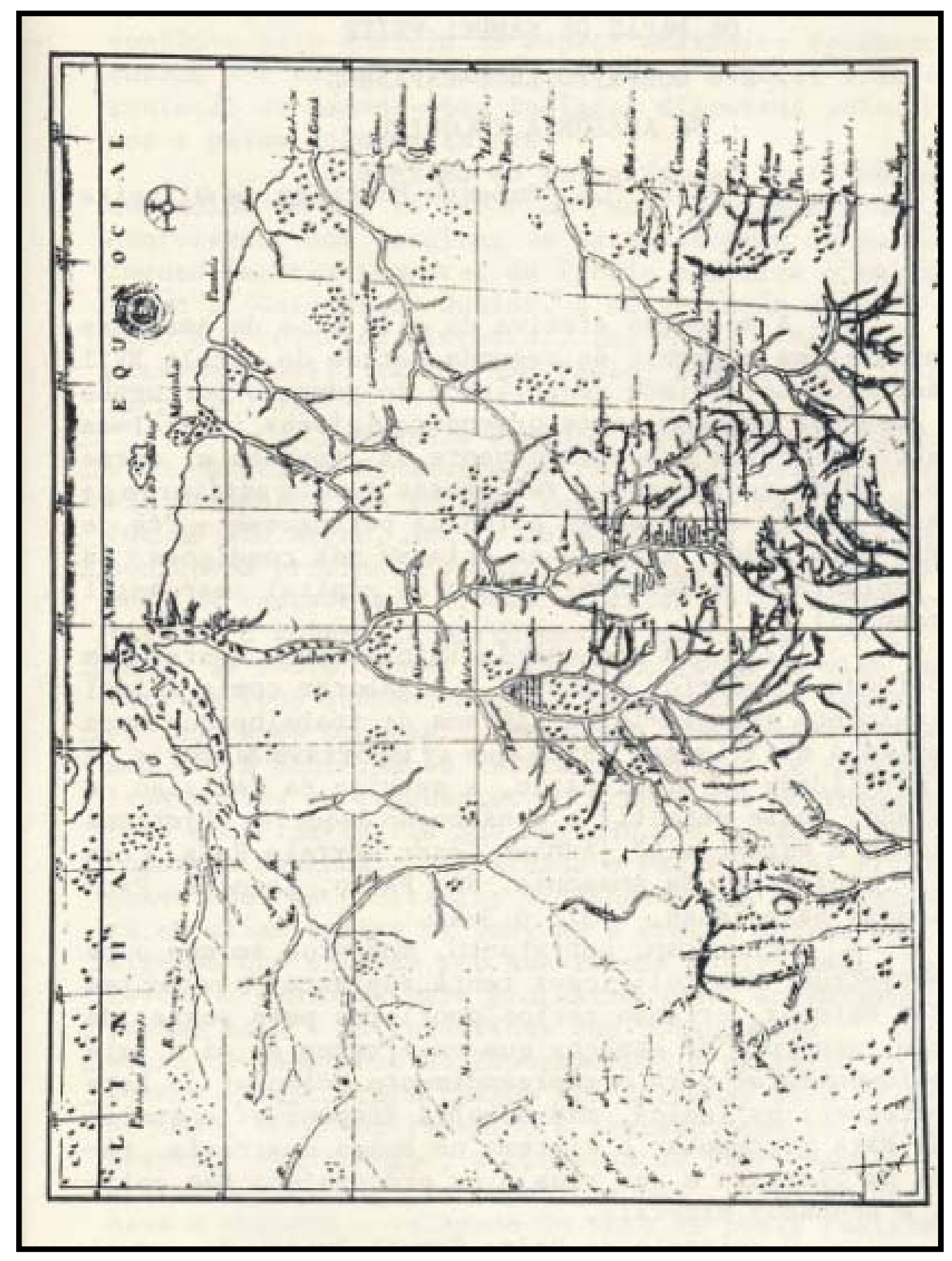

Fig. 3. Mapa del reconocimiento del río Uaupés y su comunicación con el río Japurá. Elaborado en 1785 por el coronel Manoel da Gama Lobo d'Almada. Tomado de: Boletim de CEDEAM, no 6 (Manaus: Universidade do Amazonas, 1985). 


\section{La boca más occidental del río Japurá}

La entrada en el río Japurá de las partidas con objetivos demarcatorios ocurrió en 1782. El 21 de febrero se presentó el comisario español con veinte canoas y doscientas dos personas, uniéndose al comisario portugués, que a su vez traía consigo veinticuatro canoas y trescientas treinta y cuatro personas. Todo este aparato (44 canoas y 536 personas) no resolvería en nada la demarcación. Muy por el contrario, a partir de ahí los conflictos y dificultades tomaron tal proporción que volvieron imposible la ejecución de los trabajos pretendidos y concebidos por el tratado.

Muchos fueron los motivos que contribuyeron al fracaso de esta expedición demarcatoria. Los problemas iniciales fueron comentados por el ministro Martinho de Mello y Castro en carta a Pereira Caldas, destacando como el principal, la falta de planificación por parte del primer comisario Chermont, quien por haber ignorado las informaciones del diario escrito por el segundo comisario Wilckens, en el momento de su viaje para el examen anticipado del Japurá, desechó informaciones que podrían haber sido útiles a la misión:

[...] que únicamente lo más difícil de vencer en el Río Japurá, eran la Cascada de Uviá, y la que seguía después de ella. Que el medio de facilitar estos tránsitos, o de hacerlos menos incómodos, era anticipar la exploración de ellos durante el tiempo de las aguas, o de las lluvias, que acostumbran venir en mayor abundancia a partir del 20 de mayo; y que para conseguir esto era indispensablemente necesario que él y el comisario español, que lo había de acompañar, entrasen en el referido Japurá a más tardar a principios del mes de diciembre [...] no era menos necesario mandar con anticipación de algunos días a algunas de las personas que acompañaron al comisario Wilckens [...], con orden de subir a lo alto de la Cascada de Uviá y allí construir canoas en la forma en que precedentemente habían hecho, de suerte que estuviesen listas cuando los comisarios portugués y español llegasen a aquel sitio: Y si con esta pequeña y anticipada expedición se mandase al matemático Joseph Simões de Carvalho para dirigir, y con orden de explorar aquellos distritos mientras no llegasen los referidos comisarios, tal vez proveído de poca gente, pero escogida y capaz de ayudarlo, hiciese útiles progresos que facilitasen y abreviasen la demarcación por aquella parte [...] Se ve por los hechos que no se hizo ningún plano de la exploración de aquel río, ni se pronunció ni una palabra sobre la continuación de la demarcación de él por encima de la Cascada de Uviá, ni del reconocimiento de las sierras que se veían desde aquel distrito: Se ve que don Francisco Requeña, queriendo desviar cuanto pudiese la demarcación por aquella parte y aprovechándose hábilmente del incomprensible silencio del comisario portugués en un punto tan importante, se cuidó de entretenerlo con oficios repetidos y muchos de ellos insignificantes, en diferentes aspectos, desde la entrada 
del Japurá, excepto en el de la discusión de la boca más occidental del referido río, denominada Auatyparaná ${ }^{27}$.

A pesar de esto, partió la expedición. El 21 de febrero de 1782 los dos comisarios con la inmensa comitiva entraron al Japurá, y el 18 de marzo alcanzaron la boca del Río Apaporis, después de un prolongado y lento viaje de veintiséis días, no habiendo en este trayecto ya conocido, cascadas u obstáculos que lo dificultasen. Y fue justamente en la boca del Apaporis donde se inició el proceso que reduciría la importantísima demarcación del Japurá a un caos de desavenencias y que en el futuro causaría la suspensión de las demarcaciones.

Después de la llegada al Apaporis, Requeña declaró a través de oficio que la frontera y los trabajos demarcatorios no deberían continuar por el Japurá, sino por el río Apaporis. El comisario portugués, olvidándose totalmente de los términos precisos del artículo XII del Tratado Preliminar de 1777 y de las instrucciones reales recibidas por Pereira Caldas, respondió al oficio con toda la condescendencia, pareciéndole, sin embargo, que la frontera debería proseguir por el río de los Enganos o Comiari. Después de una absurda discusión sobre cuál de los ríos se debía preferir, redactaron un "Término" aún más absurdo el 29 de marzo de 1782, donde se acordaba la exploración de ambos ríos, sin que se dijera ni una sola palabra sobre la continuación de la frontera o su demarcación por el río Japurá28

Como consecuencia del Término redactado en el Apaporis el viaje prosiguió por el río de los Enganos, entrando las partidas el día 6 de mayo. Resulta curioso lo que Wilckens informó en el diario de la segunda entrada en el Japurá, acerca de lo ocurrido en la exploración de una gran cascada, a la cual llegaron el 8 de mayo, muy semejante a la "Cascada Grande" del Japurá, pero

\footnotetext{
27 “[...] que unicamente havia no Rio Japurá mais difícil de vencer, eram a Cachoeira de Uviá, e a que depois dela se lhe seguia. Que o meio de facilitar estes trânsitos, ou de os fazer menos incômodos, era o de antecipar a exploração deles ao tempo das Águas, ou das Chuvas; que costumam vir em maior abundância depois de 20 de Maio por diante; e que para isto se conseguir era indispensavelmente necessário, que ele, e o Comissário Espanhol, que o havia de acompanhar entrassem no referido Japurá o mais tarde até o principio do mês de Dezembro [...] não era menos necessário mandar com antecipação de alguns dias, a algumas das pessoas que acompanharam o segundo Comissário Wilckens, [...] com ordem de subir ao alto da Cachoeira de Uviá, e ali construir canoas, na forma, que precedentemente haviam feito, de sorte que estivessem prontas quando os Comissários Portugueses ,e Espanhóis chegassem aquele sítio: E se com esta pequena, e antecipada expedição, se mandasse o Matemático Joseph Simões de Carvalho para a dirigir, e com ordem de explorar aqueles distritos enquanto não chegavam os referidos Comissários, talvez que ele só munido de pouca gente, mas escolhida, e capaz de o ajudar, fizesse úteis progressos que facilitassem, e abreviassem a Demarcação por aquela parte [...] Vê-se porém pelos fatos, que se não formou algum Plano sobre a exploração daquele Rio, nem se proferiu uma só palavra sobre o prosseguimento da Demarcação dele por cima da Cachoeira de Uviá, nem do reconhecimento das Serras que se viam daquele distrito: Vê-se que Dom Francisco Requeña querendo desviar quanto pudesse a Demarcação por aquela parte, e aproveitando-se habilmente do incompreensível silêncio do Comissário Português em um ponto tão importante, cuidou em o entreter com Ofícios repetidos, y muito deles insignificantes, em pontos todos diversos da entrada do Japurá, exceto o da discussão sobre a Boca mais Ocidental do referido Rio, denominada Auatyparaná, na qual ainda assim não conveio o Comissário Espanhol sem um formal protesto, que faz inútil o seu consentimento". "Carta del Ministro de los Negocios Ultramarinos, Martinho de Mello e Castro, al Capitán General João Pereira Caldas. Mafra, 29 de agosto de 1783”, MA, APEP, caja 17, códice 1009, docs 71-116.
}

${ }^{28}$ Ibídem. 
con un camino más accesible. Donde la cascada terminaba, el río era ancho y se apreciaban sierras por todas partes, especialmente unas más elevadas en la dirección nordeste:

En este día volvió el dibujante español que había ido al examen del río por la parte superior de la cascada, el día 11 del corriente, e informó que como a día y medio de viaje se llegaría a otra cascada mucho más extensa y horrorosa que esta primera: $\mathrm{Y}$ que subiendo a lo más alto de las sierras con un telescopio, nada descubría, más que sierras continuas ${ }^{29}$.

De acuerdo con el ministro Martinho de Mello e Castro, estas informaciones habrían sido suficientes para que el teniente coronel Chermont hubiera apreciado la semejanza entre las sierras que se descubrían desde lo alto de la cascada del Japurá, descritas en el diario del reconocimiento anticipado, con éstas del río de los Enganos. Como continuación o cadena de aquéllas y estando unidas o separadas, no podían dejar de ser la cordillera de Montes de que trataba el artículo IX del Tratado de Límites, principalmente encontrándose situadas en la misma dirección donde el artículo las ubicaba. Era posible creer sin titubear que las sierras vistas, tanto del Japurá como de los Enganos, formaban la cordillera de Montes, justamente donde se debía determinar el punto fijo de la línea divisoria para, a partir de él, continuar la demarcación en dirección al oriente, exactamente como estaba especificado en dicho artículo del Tratado de Madrid ${ }^{30}$.

Con estos fundamentos el comisario portugués podría obligar al comisario español a la exploración y al reconocimiento de las sierras, exigiendo lo que pertenecía o podría pertenecer a Portugal. Desgraciadamente, para Portugal, la única perspectiva que Chermont tuvo de la cascada fueron las particularidades que presentaba, por las caídas y torrentes de agua. Esta insensibilidad le impidió volver a la cascada, y pasó a ocuparse en innumerables encuentros con el comisario español y en la exploración de varios ríos que con diferentes vueltas entraban en el río de los Enganos, sin que se pudiera apreciar cuáles eran los objetivos de estas exploraciones, puesto que parecían insignificantes para la continuación de las demarcaciones.

Mientras el comisario portugués junto con su partida se enfrascaban en estos inútiles ejercicios, Requeña intentaba obtener el máximo de información de toda el área a través de los indios Maués, que llamaba a su presencia a través del práctico conocedor de la región, "capitão do mato", de su partida. También ordenaba a su dibujante que explorase la primera y también la segunda cascada del río de los Enganos, observando cuidadosamente con el telescopio las sierras continuas que desde allí se avistaban; a las mismas que no hicieron el menor caso Chermont ni los miembros de su numerosa partida ${ }^{31}$.

\footnotetext{
29 "Neste dia voltou o Desenhador Espanhol que tinha ido ao exame do Rio pela parte superior da Cachoeira, no dia 11 do corrente, e informou que com dia e meio de viagem, chegara a outra Cachoeira muito mais extensa, e horrorosa do que esta primeira: E que subindo ao mais alto das Serras com Telescópio nada descobrira mais do que Serras continuadas". Ibídem. Las palabras se encuentran subrayadas en el documento.

${ }^{30}$ Ibídem.

${ }^{31}$ Ibídem.
} 


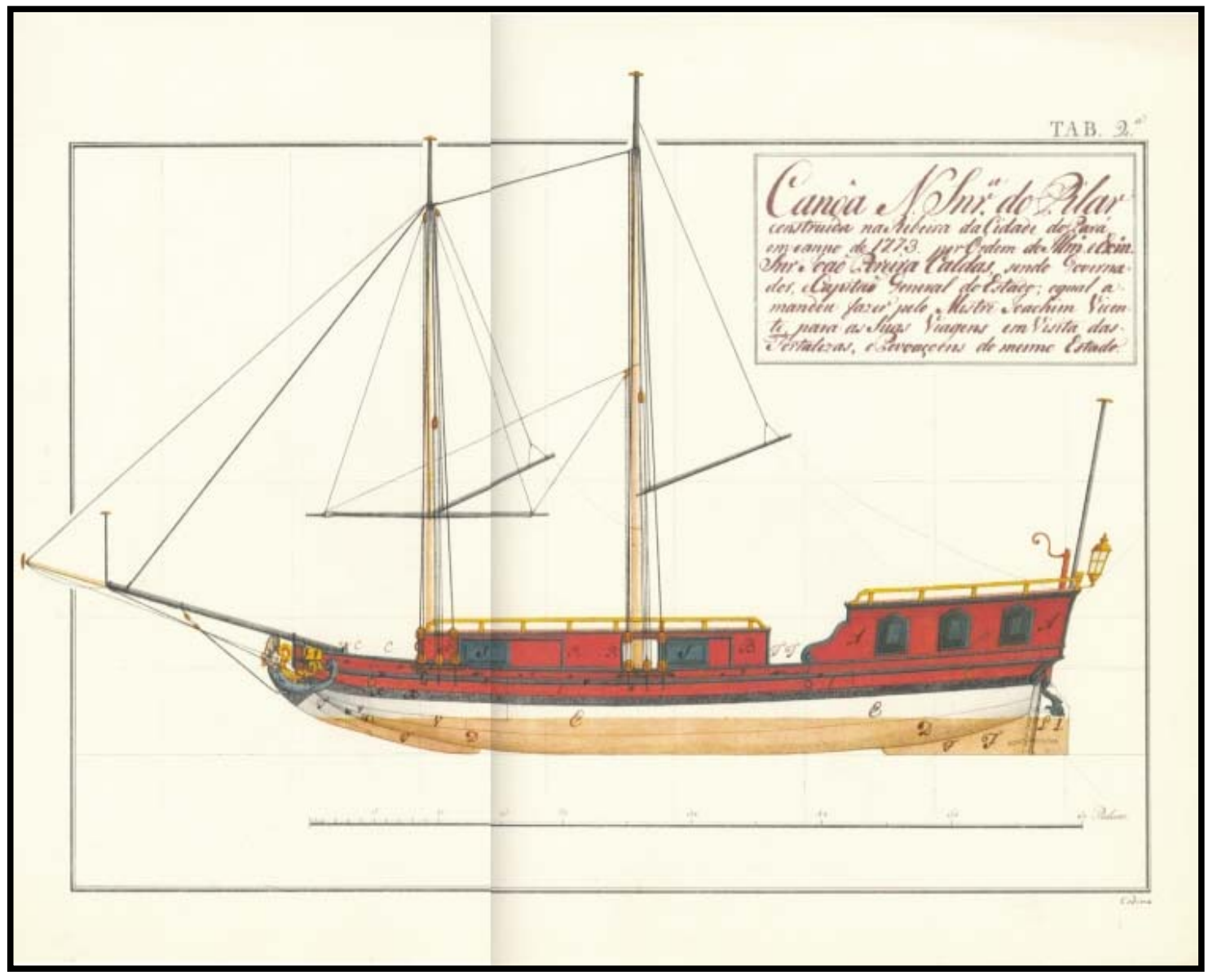

Fig. 4. Canoa Nossa Senhora do Pilar, construida por orden del capitán general João Pereira Caldas, Plenipotenciario de la Comisión Portuguesa de Demarcación de Límites del Norte, para sus viajes en la visita a las fortalezas y poblaciones del Estado. Tomado de: Livros Digitais, Série Amazoniana, Secretaria de Cultura do Estado do Amazonas (Manaus, 2002). 
Las dos partidas permanecieron en el río de los Enganos durante treinta y nueve días, partieron el 15 de junio y llegaron nuevamente a la boca del Apaporis después de cuatro jornadas de viaje. En este punto los dos primeros comisarios con sus respectivas comitivas se separaron para iniciar la exploración del río.

Esta exploración no pudo ser terminada; no porque alguien se opusiera, sino porque una violenta epidemia de fiebre la volvió imposible. La exploración se redujo a la entrada por la desembocadura el 22 de junio y el cruce de cuatro cascadas, las dos partidas llegaron el primero de julio al poblado portugués de los indios Coretús con un número considerable de personas enfermas. Por suerte los indios hicieron de sus propias casas un hospital, y trataron a los enfermos "con un cuidado, desvelo y humanidad, que causaron admiración en todos los europeos que allí se hallaban"32.

A pesar del decaimiento y aflicción de todos a causa del inmenso número de personas enfermas, durante los pocos días que permanecieron en el Apaporis el comisario español continuó examinando a los indios más prácticos de aquel lugar, llevándolos a su presencia y utilizando como intérprete al anspeçada portugués João Dias. Ni siquiera esto alertó al comisario portugués, quien si hubiera querido aprovechar esta ventaja, hubiera podido interrogar a los mismos indios, para así obtener información muy valiosa para su comisión, como lo hizo el propio Requeña con los indios del río de los Enganos.

La fiebre continuaba y pocos eran los que estaban sanos en ambas partidas. Por consiguiente, los dos comisarios resolvieron retroceder para evitar "el total exterminio de los vasallos de las dos coronas" ${ }^{\prime 3}$, como efectivamente hicieron el 6 de julio. Salieron el 9 de la boca del Apaporis y entraron en el Japurá en dirección al cuartel de la villa de Ega, lugar donde se establecieron y permanecieron por muchos años aguardando las instrucciones de sus cortes.

De esta expedición, inicialmente destinada a la demarcación del Japurá, y después de todos sus acontecimientos y de algunas conferencias exigidas por el comisario español, resultó un Término redactado el 26 de noviembre de 1782, cuyo punto más interesante es la declaración del primer comisario Chermont cuando se le preguntó sobre la dirección del curso progresivo de la demarcación y el reconocimiento iniciado:

Que habiéndose comenzado una demarcación interina en el Río Amazonas, y continuada la misma por el Río Japurá hasta la boca del Río Apaporis, donde como consecuencia de las dudas que se presentaron fue suspendido el efecto de dicha demarcación interina, y comenzado el reconocimiento de los ríos y sus colaterales, que se expresarán en el Instrumento de Convención hecho el 26 de mayo próximo

\footnotetext{
32 "Com um cuidado, desvelo, e humanidade, que fez a admiração de todos os Europeos que ali se achavam". Ibídem.

${ }^{33}$ De acuerdo con el comisario español D. Francisco Requeña, en su diario de viajes, los días 3 y 4 fueron sucesivamente dando entrada en el hospital improvisado por los indios Coretús a casi todos los hombres que hasta entonces parecían bien, quedando la partida española solamente con diecisiete sanos y la portuguesa con trece. Cf. Giraldo, Francisco de Requeña, 130.
} 
pasado por las mismas dudas; que extraídos los documentos de la sobredicha ejecución, así de la demarcación interina como del reconocimiento de los ríos expresados, para que se hicieran las debidas participaciones a los respectivos superiores; parecía que para el orden sucesivo de los reconocimientos, se debería hacer el reconocimiento de la parte superior del Río Negro y de sus ríos colaterales, por donde se infiere que deberá pasar la línea divisoria ${ }^{34}$.

Con esta declaración Chermont renunciaba a continuar la frontera por el Japurá, por el río de los Enganos y las partes superiores de ellos, y también al examen de las sierras continuas que se veían desde sus cascadas. Con este parecer daba por completa y acabada la demarcación por esta parte; y hacía ilusoria e innecesaria la importantísima demarcación del Japurá. De este procedimiento podría resultar una porción menor de territorio para Portugal.

\section{Nuevas estrategias y otros agentes}

Las actitudes asumidas por el primer comisario Chermont (la conveniencia del Término firmado el 26 de marzo de 1782 en la boca del Apaporis, la permanencia de treinta y nueve días en el río de los Enganos en inútiles averiguaciones, el desprecio por el reconocimiento de las sierras continuas que podrían ser la cordillera de Montes, y finalmente, la declaración realizada en el Término del 26 de noviembre de 1782), fueron consideradas por el ministro Martinho de Mello e Castro como una secuencia de desatinos extremadamente perjudiciales para Portugal, dejando a la corte portuguesa sin argumentos para negociar con Madrid ${ }^{35}$.

A partir de estos acontecimientos las directrices trazadas para las demarcaciones fueron radicalmente alteradas. Para el teniente coronel Chermont los resultados de sus "desatinos" fueron su retiro del cargo de primer comisario y su transferencia a la Villa de Barcelos a finales de $1783^{36}$, con orden de dejar los papeles, cartas, registros y todo lo que fuese pertinente para los trabajos de demarcación de límites al segundo comisario Wilckens, encargado de ejercer el

\footnotetext{
34 “Que tendo se principiado uma Demarcação interina no Rio Amazonas, e continuada a mesma pelo Rio Japurá até a Boca do Rio Apaporis, onde em conseqüência das dúvidas então produzidas, foi suspendido o efeito da dita Demarcação interina, e principiado o do reconhecimento dos Rios, e seus Colaterais, que se expressaram no Instrumento de Convenção feito em 26 de Março próximo passado em razão das mesmas dúvidas; que extraídos os Documentos da sobredita execução assim da Demarcação interina, como do reconhecimento dos Rios expressados para se fazerem as devidas participações aos respectivos superiores; parecia que por ordem sucessiva dos reconhecimentos se deveria fazer o reconhecimento da parte superior do Rio Negro, e de seus Rios Colaterais, por onde se infere deverá passar a Linha Divisória". "Carta del Ministro de los Negocios Ultramarinos, Martinho de Mello e Castro, al Capitán General João Pereira Caldas. Mafra, 29 de agosto de 1783”, MA, APEP, caja 17, códice 1009, docs. 71-116. Las palabras se encuentran subrayadas en el documento.

35 Ibídem.

${ }^{36}$ A pesar de haber sido separado del mando de la partida portuguesa, Chermont se mantuvo en Barcelos en el servicio de las demarcaciones y recorrió el río Urubú en 1787, escribiendo el Diário de Navegação do rio Urubú, 1787 - Mapa do rio Urubú, 1787. Cf. Reis, História, 139.
} 
mando interino de la partida portuguesa hasta la llegada del teniente coronel Mardel, nombrado primer comisario en sustitución del anterior ${ }^{37}$.

Junto con la orden de destitución y transferencia de Chermont, Pereira Caldas fue informado de las instrucciones que recibió el coronel Manoel da Gama Lobo d'Almada ${ }^{38}$, de seguir hacia la capitanía del río Negro y la orden para que, llegando a Barcelos, le fuese dado el comando de la parte superior del río Negro, haciéndolo partir inmediatamente para dirigir la exploración y reconocimiento de los ríos y canales existentes entre el Forte de São José de Marabitanas y las cascadas, así como también las comunicaciones posiblemente ubicadas río abajo. La tercera orden consistía en su partida para la Villa de Ega para intentar retomar la conducción de los negocios de la demarcación ${ }^{39}$.

En esta misma ocasión vinieron de Portugal las instrucciones sobre la llegada del naturalista Alexandre Rodrigues Ferreira que, acompañado por su equipo técnico formado por el jardinero botánico Agostinho José do Cabo y dos dibujantes, Joaquim José Gondina y José Joaquim Freire, traía consigo la orden del ministro "de averiguar inscripciones, costumbres, literaturas, además del peso enorme de las producciones de los tres reinos" $"$.

Así como Martinho de Souza Albuquerque, gobernador del Estado del Grão-Pará y río Negro, Pereira Caldas recibió la orden de proveer lo que fuese necesario a las expediciones del naturalista en el alto río Negro.

Los dichos naturalistas deben emplearse bajo las órdenes de Vuestra Señoría en examinar y describir todo lo que hubiese en ese Estado relativo a la historia natural, $\mathrm{y}$ en recoger y preparar lo que se debe remitir a esta Corte [...] Y en esta inteligencia les determinará Vuestra Señoría los sitios donde han de ir, la forma en que le parezca más acertado; mandándolos auxiliar en las jornadas o viajes que

\footnotetext{
37 “Carta del Ministro de los Negocios Ultramarinos, Martinho de Mello e Castro, al Capitán General João Pereira Caldas. Mafra, 29 de agosto de 1783", MA, APEP, caja 17, códice 1009, docs. 121-128 (A).

${ }^{38}$ Lobo d'Almada llegó a la Amazonía en 1770 a ocupar el puesto de capitán y designado para el comando de la fortaleza de Gurupá y gobierno de la región. Permaneció en Macapá hasta octubre de 1771, cuando fue ascendido a teniente coronel. En 1773 regresó a Macapá donde se mantuvo hasta 1784, año en que fue ascendido al puesto de coronel y propuesto para el comando y gobierno militar del alto río Negro. Cf. Reis, História, 142 y Lobo d'Almada: um estadista colonial, manuscrito (1940), 7-10.

39 "Carta del Ministro de los Negocios Ultramarinos, Martinho de Mello e Castro, al Capitán General João Pereira Caldas. Mafra, 29 de agosto de 1783”, MA, APEP, caja 17, códice 1009, docs. 121-128 (A).

40 "De averiguar inscrições, costumes, literaturas, além do peso enorme das produções dos três reinos". Natural de Bahía y licenciado en Filosofía Natural por la Universidade de Coimbra, llegó a Belém del Grão-Pará en octubre de 1783 y hasta febrero de 1785, fecha en que llegó a la barra del río Negro. Realizó viajes a la isla de Marajó, al río Tocantins y a los alrededores de Belém y río Amazonas arriba, pasando entonces a realizar observaciones en la parte superior del río Negro, arriba de Barcelos. En marzo de 1786 partió en visita al bajo río Negro y al río Branco y, en agosto de 1788, dio inicio a la exploración del río Madeira, pasando por el Mamoré, Guaporé y por el fuerte Príncipe de la Beira, llegando a la Vila Bela do Mato Grosso en octubre de 1789. Retornó a Lisboa en octubre de 1792 después de casi diez años de vida y trabajo en la Amazonía. Entre su numerosa documentación y manuscritos, produjo el Diario da Viagem Filosófica ao Rio Negro, resumiendo las actividades de cuatro años de expedición. Cf. http:// www.institutopaubrasil.org.br/personal.htm.
} 
hicieren, con embarcaciones, gente y lo demás que fuere preciso, así para su transporte como para sus comidas ${ }^{41}$.

Esta sería una preocupación adicional para el plenipotenciario de las demarcaciones. El río Negro nunca fue abundante ni en "gente", aquí representada por los indios (mano de obra única e indispensable, tanto para acompañar las expediciones como guías, remeros, pescadores y cazadores, como para construir embarcaciones) ni en "comidas", puesto que la harina, alimento principal de la región, nunca fue suficiente, principalmente durante el periodo de las demarcaciones de fronteras ${ }^{42}$. También existía la necesidad apremiante de atender las exigencias concernientes a las expediciones que deberían ser realizadas por el coronel Lobo d'Almada, especialmente porque la orden metropolitana recibida, de confiarle el comando del alto río Negro, traía severas críticas con respecto al precario conocimiento de los ríos y canales obtenido hasta aquel momento y, con gran vehemencia, revelaba la enorme confianza en el hombre destinado a ejecutar el trabajo deseado:

En el mapa general del Río Negro que Vuestra Señoría remitió a esta secretaría de Estado, y que tiene por título Mapa Geográfico da Capitania do Rio Negro donde van anotadas sus comunicaciones con el Japurá, se apuntan cinco de las dichas comunicaciones o canales [...]: Si estas comunicaciones han sido o no bien conocidas desde la parte del Río Negro, ha sido hasta ahora un misterio para esta Corte, y por este motivo debe Vuestra Señoría ordenar al sobredicho coronel Manoel da Gama Lobo que se ocupe en el trabajo y diligencia de examinar él mismo y hacer examinar los mencionados tránsitos, comenzando como digo arriba por los que quedaren entre S. Joseph y las cascadas del Río Negro, y descendiendo desde aquí hacia abajo hasta las otras que señala el Tratado del que he hablado, haciendo Vuestra Señoría de todas una exacta, individual y circunstanciada información, que hace mucho se espera y hasta ahora no se ha visto. Al sobredicho coronel socorrerá Vuestra Señoría con todo cuanto le fuese necesario de gente,

\footnotetext{
41 "Os ditos naturalistas, e Riscadores, devem empregar-se debaixo das Ordens de V. S $\mathrm{S}^{\mathrm{a}}$ em examinar, e descrever tudo o que houver nesse Estado relativo à História Natural, e em recolher, e preparar o que se deve remeter a esta Corte [...] E nesta inteligência lhes determinará V.S os Sítios onde hão de ir, na forma que lhe parecer mais acertado; mandando-os auxiliar nas jornadas, ou viagens que fizerem, com Embarcações, Gente, e o mais que se fizer preciso, assim para o seu transporte, como para as suas Comedorias". "Carta del Ministro de los Negocios Ultramarinos, Martinho de Mello e Castro, al Capitán General João Pereira Caldas. Mafra, 29 de agosto de 1783", MA, APEP, caja 17, códice 1009, docs. 147-149.

${ }^{42}$ Se percibe en otra ocasión la angustia de Pereira Caldas por no poder solucionar las necesidades de las expediciones: "Sobre os noventa índios, que pelo menos, V.S a me pede das Povoações deste Rio, [...] e sobre a remessa de alguns Militares, estou na diligência de fazer aprontar, e expedir o que unicamente for possível desta qualidade de socorro, atento a falta em que do maior preciso número de uns, e outros indivíduos aqui me acho, para a tantas e diferentes repartições acudir com a indispensável urgência, e ainda agora mais cresce a diligência do Doutor Naturalista, e seus companheiros, que tendo aqui chegado proximamente, já de quarenta e tantos índios que trouxeram da Capitania do Pará, se ausentou a maior parte, sem que com o resto se possa da mesma forma contar". "Carta del Capitán General João Pereira Caldas al Coronel Manoel da Gama Lobo d'Almada. Barcelos, 8 de abril de 1785”, Demarcações no Alto Rio Negro-Cartas e Relatórios, 1783 a 1785, MA, Livro Cedeam E-025, AHU, docs. 114-119.
} 
canoas, víveres, instrumentos y lo demás indispensable para semejantes expediciones [...] que no lleve matemáticos ni ingenieros por no haberlos en este cuartel, basta que sea acompañado por buenos prácticos, que no podrá dejar de haberlos en ese río, y de gente que soporte el trabajo, y no de los que fallecen en él, como hasta ahora infelizmente hemos visto, confiando Su Majestad en la honra del sobredicho oficial por las consistentes pruebas que de ella tiene dadas, que él será ejemplo y modelo de los que lo acompañaren en el desempeño de sus obligaciones sobre este importante artículo, internándose cuanto le fuere posible en las referidas comunicaciones, hasta que se pueda hacer juicio cierto de lo que ellas tienen o pueden tener con los ríos o canales de la parte opuesta del Japurá ${ }^{43}$.

\section{Manoel da Gama Lobo d'Almada: explorador y estadista}

Lobo d'Almada, considerado por todos como un ardiente patriota, "hombre ilustrado e inteligente, gozando, como ingeniero militar que era, de renombre en la Corte de Lisboa, era el tipo perfecto de militar disciplinado"44 y conocedor de los problemas y carencias del sertón amazónico, tanto por el largo tiempo en que había vivido en la Amazonía como por su experiencia profesional; era considerado la persona indicada para suplir la necesidad de informaciones precisas y seguras sobre la región del alto río Negro y, principalmente, informaciones sobre las comunicaciones del río Negro con el Japurá, de suma importancia para la demarcación de las líneas de frontera.

Las informaciones obtenidas a través de las exploraciones realizadas en 1781 por Henrique João Wilckens, Francisco José de Lacerda e Almeida y Joaquim José Ferreira; por los estudios efectuados por Felippe Sturn, Sebastião José, João André Shwebel, Adam Leopoldo de

\footnotetext{
43 "No Mapa geral do Rio Negro que V.S remeteu a esta Secretaria de Estado, e que tem o título Mapa Geográfico da Capitania do Rio Negro onde vão notadas as suas Comunicações com o Japurá se apontam cinco das ditas Comunicações, ou Canais [...]: Se estas Comunicações porém são, ou não bem conhecidas da parte do Rio Negro, isto tem sido até agora um mistério para esta Corte, e por este motivo deve V.S ordenar ao sobredito Coronel Manoel da Gama Lobo, que se não poupe a trabalho, ou diligência alguma para examinar ele mesmo, e fazer examinar os mencionados trânsitos, começando como acima digo, pelos que ficarem entre S. Joseph, e as Cachoeiras do Rio Negro, e descendo daqui para baixo às outras que aponta o Tratado de que acima falo, fazendo V.S de todas una exata, individual, e circunstanciada informação, que há três se espera, e até agora não tem vindo. Ao sobredito Coronel socorrerá V.S ${ }^{\mathrm{a}}$ com tudo quanto lhe for necessário de Gente, Canoas, Víveres, Instrumentos, e o mais que se faz indispensável para semelhantes expedições [...] que não leve Matemáticos, nem Engenheiros pelos não haver neste Quartel, basta que seja acompanhado de bons práticos, que não pode deixar de os haver desse Rio, e de Gente suportadora de trabalho, e não dos que falecem, y esmorecem nele, como até agora infelizmente temos visto, confiando Sua Majestade na honra do sobredito Oficial pelas consistentes provas que dela tem dado, que ele será o exemplo, e o modelo dos que o acompanharem no desempenho de suas obrigações sobre este importante artigo, internando-se quanto lhe for possível pelas referidas Comunicações até se poder fazer juízo certo do que elas tem, ou podem ter com os Rios, ou Canais da parte oposta do Japurá". "Carta del Ministro de los Negocios Ultramarinos, Martinho de Mello e Castro, al Capitán General João Pereira Caldas. Mafra, 29 de agosto de 1783”, MA, APEP, caja 17, códice 1009, docs. 121-128 (A).

44 "Homem ilustrado e intelligente gozando, como engenheiro militar que era, de renome até na Corte de Lisboa, era um typo perfeito de militar arregimentado". Palma Muniz, "Limites Municipais do Estado do Pará", Anales de la Biblioteca y Artículo Público de Pará, tomo IX (Belém, 1916), 406-414, citado en Reis, Lobo, 9.
} 
Breuning, con las observaciones astronómicos del padre Ignacio Swemartoni; así como las informaciones recogidas de los moradores de la región, las cuales el sargento mayor Euzebio Antonio de Ribeiros utilizó para elaborar, en 1780, el "Mappa geographico da Capitania do Rio Negro" 45 , no eran satisfactorias para un total y perfecto conocimiento de la región. Muy por el contrario, diseñaban un confuso laberinto líquido.

En abril de 1784 Lobo d'Almada recibió de Pereira Caldas instrucciones minuciosas referentes a sus atribuciones y obligaciones. De carácter técnico y naturaleza política, consistían en la organización de los poblados, la defensa del territorio, el trato con los indios, el reconocimiento de los cursos fluviales y la intensificación del cultivo del añil. En mayo del mismo año se instaló en São Gabriel da Cachoeira, y allí fijó la sede de su unidad administrativa. Auxiliado por el teniente Marcelino José Cordeiro, director de la población y respetado como gran especialista en fronteras, inició su principal tarea: las exploraciones geográficas ${ }^{46}$.

Los dos años siguientes se lanzó a cumplir la empresa. Demostrando capacidad y entusiasmo en vencer la precariedad de las condiciones en que viajaba, muchas veces en frágiles embarcaciones (igarités) y la propia adversidad ofrecida por la naturaleza de la región, conquistó el respeto y admiración de sus compañeros y confirmó la desmedida confianza real que le fue depositada, repitiendo muchas veces:

Yo mismo voy personalmente a todos estos exámenes y averiguaciones: Porque yo no informaré de cosa alguna que yo mismo no tenga vista palpablemente: Porque yo no soy capaz de consentir que los que me acompañan pasen por trabajo o peligro alguno, en que no sea el primero en dar el ejemplo $[\ldots]^{47}$.

La dedicación de Lobo d'Almada a sus actividades le rindió muchos frutos, entre ellos y tal vez el más importante fue el hallazgo de las comunicaciones entre los ríos Negro y Japurá, puesto que esta cuestión era considerada vital para la metrópoli. La primera por el Yucari-CananariApaporis. La segunda por el Tiquié-Japuparaná-Piriparaná-Apaporis-Marutiparaná. La tercera por el Ununhan-Ussaparaná-Apaporis. Además constató a través de un riguroso mapa las comunicaciones por los ríos Capuri, Marié, Chivara o Teya, Unuixi y Urubaxi. Todas eran por tierra. Algunas podrían ser recorridas en pocas horas y otras podían demorar hasta nueve días ${ }^{48}$.

\footnotetext{
45 "Mappa geographico da Capitania do Rio Negro, onde são notadas as suas comunicações com o Rio Japurá, pelos Rios Urubaxi, Unuixi, Chimará, Maria, e Uaupés, que desagoão no dito Rio Negro e se comunicão, com os Rios Maroti-paraná, Amanui-paraná, Pureo, Veya, e Uaupuapori, que desagoão no Japura”, es el título del documento. Reis, Lobo, 10.

${ }^{46}$ Ibídem, 11.

47 "Eu mesmo vou pessoalmente a todos estes exames e averiguações: Que eu não informarei de coisa alguma que eu mesmo não tenha visto palpavelmente: Que eu não sou capaz de consentir que os que me acompanham passem por trabalho ou perigo algum, em que não seja o primeiro a dar-lhe o exemplo[...]". "Carta del Coronel Lobo d'Almada al Capitán General João Pereira Caldas. São Gabriel da Cachoeira, 13 de Julio de 1784”, citado en Ibídem, 56-61.

${ }^{48}$ Ibídem, 12-15.
} 


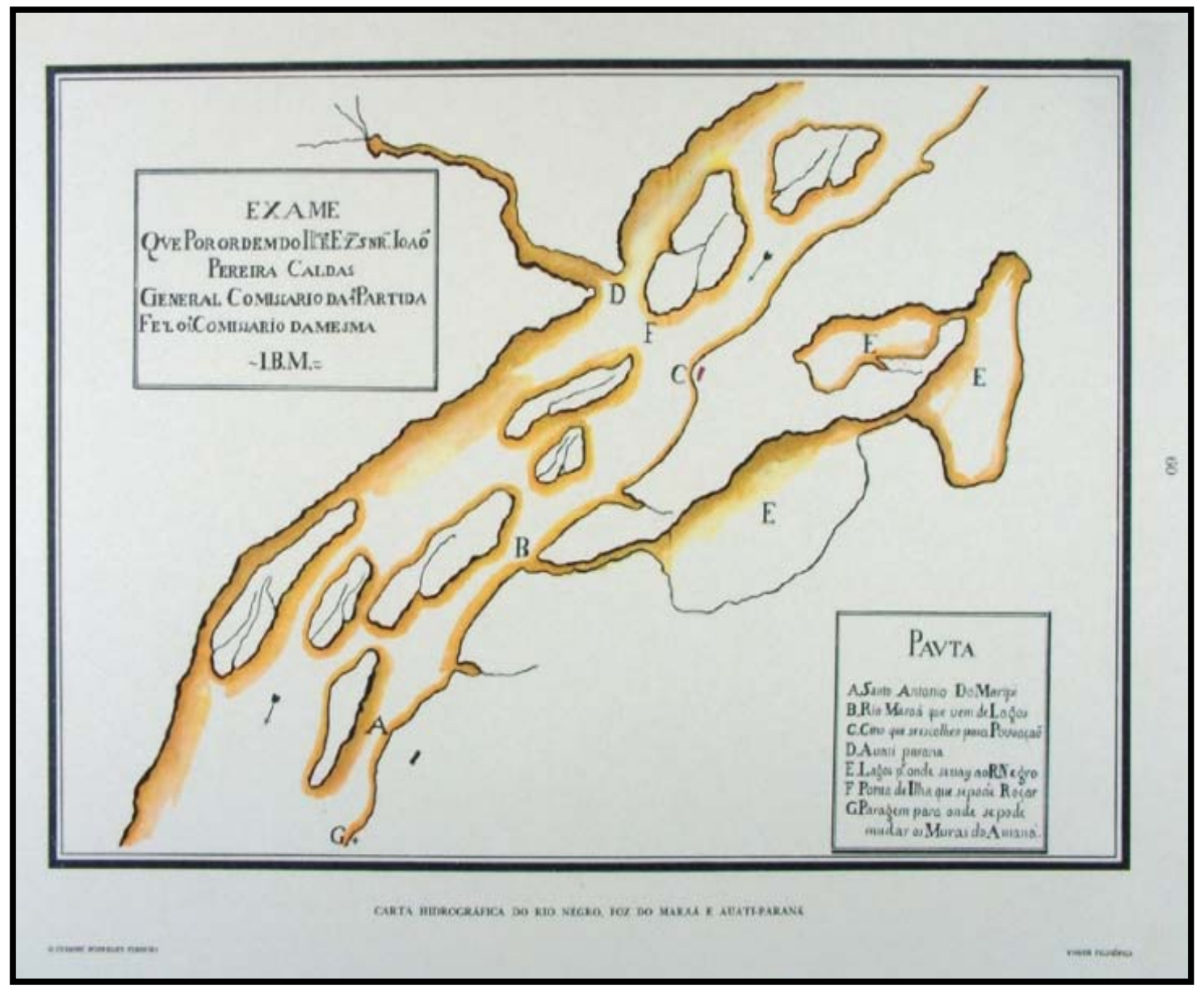

Fig. 5. Carta hidrográfica del río Negro, Foz do Maraã y Auatiparaná. Mapa elaborado durante la expedición del naturalista Alexandre Rodrigues Ferreira (1783-1792). Tomado de: Livros Digitais, Série Amazoniana, Secretaria de Cultura do Estado do Amazonas (Manaus, 2002). 
Mientras Lobo d'Almada se ocupaba en realizar su tarea, Pereira Caldas trataba de cumplir la tercera orden recibida. Siguió para Ega con el firme propósito de defender los intereses de la Corona portuguesa, al recibir de Mello e Castro instrucciones claras sobre la forma y los puntos que deberían ser negociados con Francisco Requeña.

Porque nuestra certeza es que la demarcación debe necesariamente correr, o por el Río Japurá, o por alguno de los ríos que en él se juntan y que se inclinan más hacia el rumbo del norte: hallándose ya comenzada, pero incompleta, la exploración y reconocimiento, así del dicho Río Japurá, como del Río de los Enganos, o Comiari, y del Apaporis; proponga Vuestra Señoría al dicho Requeña que no tratándose al presente ni de la inteligencia de los Tratados, ni por cuál de los sobredichos ríos deba correr la demarcación, sino únicamente de la exploración y reconocimiento de ellos, se prosiga en esta conformidad con el mismo reconocimiento y demarcación, ya sea con las partidas juntas o divididas en partes, hasta que se tenga un cabal conocimiento de los mismos ríos. Si el dicho D. Francisco Requeña no estuviese de acuerdo con este razonable arbitrio, Vuestra Señoría le hará una protesta por escrito, en la que le muestre que quiere hacer la demarcación a su arbitrio y quiere que las dos Cortes ignoren aquí lo mismo que ellas procuran y deben saber ${ }^{49}$.

Desde el punto de vista lusitano la conferencia entre los dos comisarios no produjo resultados convenientes. Requeña se rehusó a cualquier tipo de acuerdo sobre el tema en cuestión, restándole a Pereira Caldas redactar la protesta y suspender las demarcaciones hasta que las Coronas ibéricas llegasen a un acuerdo sobre el tema, hecho que nunca ocurrió.

Este fue el periodo más promisorio en relación con las exploraciones y reconocimientos de la cuenca amazónica. Los demarcadores portugueses, ocupados en seguir los dictámenes del Tratado Preliminar, quedaron libres de este trabajo y comenzaron a recorrer los ríos, examinando detenidamente sus cursos y afluentes, como también la población indígena que los habitaba. De esas ricas e importantes excursiones resultaron mapas, coordenadas y una gran diversidad de datos sobre la región y sus alrededores. Son de este momento el hallazgo de las dos comunicaciones entre los ríos Japurá y Negro, la exploración del río Branco por Lobo d'Almada, la navegación del río Urubu por Chermont, el reconocimiento de la unión entre el Waupés con el Japurá por Mardel, la subida de Euzébio Antônio de Ribeiros por el Cauaboris y

\footnotetext{
49 “Que nesta certeza, e na de que a Demarcação deve necessariamente correr ou pelo Rio Japurá, ou por algum dos Rios que nele se ajuntam, e que mais inclinam ao rumo do Norte: achando-se já principiada, mas incompleta a exploração, e reconhecimento assim do dito Rio Japurá: como do Rio dos Enganos, ou Comiari, e do Apaporis: Propõe V.S a ao dito Requeña que não se tratando presentemente nem da inteligência dos Tratados, nem por qual dos sobreditos Rios deva correr a Demarcação, mas unicamente da exploração, e reconhecimento deles, se prossiga nesta conformidade, o mesmo reconhecimento e exploração, ou seja com as partidas juntas, ou divididas em partes até se ter um Cabal conhecimento dos mesmos Rios. Se o dito D. Francisco Requeña se não quiser conformar com este racionável arbítrio, V.S ${ }^{a}$ lhe fará um Protesto por Escrito, em que lhe mostre que ele quer fazer a Demarcação a seu arbítrio, e quer que as duas Cortes ignorem aquilo mesmo que eles procuram e devem saber". "Carta del Ministro de los Negocios Ultramarinos, Martinho de Mello e Castro, al Capitán General João Pereira Caldas. Mafra, 29 de agosto de 1783", MA, APEP, caja 17, códice 1009, docs. 132-145 (B).
} 
las observaciones astronómicas en el río Negro hechas por Antônio Pires da Silva Pontes y Lacerda y Almeida ${ }^{50}$.

Al mismo tiempo que los portugueses se ocupaban en esta tarea, los españoles aprovechaban para establecerse en el Solimões. Requeña, a pesar de que seguía pidiendo la reanudación de los trabajos demarcatorios, aprovechaba para ejercer un gobierno absoluto en esta área, acompañado incluso de su familia, que también había venido a instalarse en Ega ${ }^{51}$.

Mientras las cortes ibéricas no llegaban a un acuerdo para reanudar los trabajos en la Amazonía, los españoles continuaban explorando los ríos, formando núcleos poblacionales, cobrando impuestos, ampliando la agricultura, legislando y, muchas veces, exigiendo de las autoridades lusitanas providencias, satisfacciones, víveres y remesas para su hacienda; todo esto sin sufrir la menor intervención portuguesa ${ }^{52}$.

El único que sospechó que las intenciones españolas eran las de irse apoderando poco a poco del territorio amazónico, fue el teniente coronel Mardel. En innumerables cartas y oficios comunicó a Pereira Caldas y al ministro Mello e Castro sus desconfianzas, consideradas por este último como pura imaginación de una persona incompetente para el servicio:

Estas desconfianzas repetidas en diversas cartas del teniente coronel João Baptista Mardel tienen mucho de castillos al viento y más parecen fundadas en su desbocada imaginación que en algún principio sólido; y en esta inteligencia las debe Vuestra Señoría despreciar, mientras no vea hechos que claramente muestren lo que el dicho Mardel insinúa con pocos discernimientos y menos verosimilitud [...] Si los españoles se han aprovechado del tiempo para explorar, como se les imputa, todo aquel país, por qué no hacen los portugueses lo mismo, tomando conocimiento de todos aquellos distritos, y haciendo ver a esta Corte que no viven, como se hallan, en una profunda ociosidad [...] Esto es lo que Vuestra Señoría debe responder al teniente coronel Mardel, el cual viene dando pruebas, de diverso modo, de ser tan hábil para el servicio [...] como lo fue su predecesor ${ }^{53}$.

\footnotetext{
${ }^{50}$ Reis, História, 139.

${ }^{51}$ D. Maria Luisa, esposa de Requeña, llegó en diciembre de 1783 con una comitiva compuesta de 137 personas. Traía en su compañía sus cinco hijos. Su belleza y la educación de sus hijas causaron gran admiración, suscitando versos y comentarios curiosos, como los de Chermont: "O vestuário Guayaquelenho, é do nosso parecer demasiadamente fresco; o comprimento da Saia não excede a barriga da perna; [...] é celebríssimo na verdade o tal vestuário, pois persuado-me que em Mulher grossa, pelo muito que descem o cós da Saia, pela parte de diante, que não deixará de divizar-se a proeminência do Monte de Vênus". "Carta del Comandante Jozef Mazorra a D. Francisco Requeña. Destacamiento de Camuchiro, 13 de diciembre de 1783" y "Carta del Teniente Coronel Theodozio Constantino de Chermont al Capitán General João Pereira de Caldas. Ega, 25 de diciembre de 1783”. Demarcações no Alto Rio Negro-Cartas e Relatórios, 1783 a 1785, MA, Livro Cedeam E-025, AHU, 78-79 y 82-86; Reis, História, 140.

${ }_{53}^{52}$ Reis, História, 140 y Lobo, 21.

53 "Estas desconfianças repetidas em diversas Cartas do Tenente Coronel João Baptista Mardel tem muito de Castelos ao vento e mais parecem formadas na sua esquentada imaginação, que em algum princípio sólido; e nesta inteligência as deve V.S desprezar enquanto não vir fatos que claramente lhe mostrem o que o dito Mardel insinua com poucos
} 
Solamente en 1788, cuando Lobo d'Almada, nombrado gobernador de la Capitanía el año anterior, asumió el comando de la comisión de límites portuguesa en lugar de Pereira Caldas (que se enfermó y solicitó dispensa de los servicios reales y retornó a Lisboa), fue que el comisario Requeña y los españoles conocieron un adversario a la altura para contener sus intenciones y avances en la Capitanía del río Negro.

Enterándose de la situación reinante, tanto en relación con las divergencias existentes entre la misma partida portuguesa, como a los desmanes españoles, Lobo d'Almada ordenó poner fin a los desacuerdos internos y definió una estrategia pacífica y cautelosa, para no dar motivos de ofensa a Requeña; una estrategia basada en la vigilancia y en las prohibiciones, con la intención de detener las arremetidas españolas y, con esto, obligarlos a abandonar la región.

Para ello, reiteró las órdenes dadas en Tabatinga y en el Iça para que nadie atravesase la frontera sin su autorización escrita. Consciente de la llegada de refuerzos españoles de Mainas para Ega, ordenó a las autoridades civiles y militares del Solimões que se mantuviesen atentas a los movimientos españoles. Reforzó los puestos de Tabatinga, Javar, Ega e Iça, y ordenó prudencia y rigor en la vigilancia. Políticamente mantuvo una correspondencia cortés y solícita con el comisario español. En Ega, Wilckens tenía órdenes de no descuidar la política de la buena vecindad y la diplomacia. De acuerdo con el historiador Arthur Cezar Ferreira Reis, Lobo d'Almada además de excelente militar era un fino político ${ }^{54}$.

El golpe final ocurrió en 1791 cuando ordenó la ocupación del lago de Cupacá, donde los españoles ya pretendían establecerse, prohibiéndoles la entrada en territorio portugués, aunque estuvieran al servicio de su comisario. Lobo d'Almada le anunció a Requeña la decisión tomada, le recordó los excesos cometidos por la partida española y afirmó que no aceptaría más esta situación:

El abuso que se ha hecho de una simple licencia que se dio para que la partida de Vuestra Señoría pudiera hacer un poco de pesca, y nada más; cuya licencia fue además de un puro obsequio de condescendencia del Sr. João Pereira Caldas, y de Chermont para con Vuestra Señoría, el efecto de los sentimientos de hospitalidad con que siempre deseamos tratar a Vuestra Señoría, y a toda la partida bajo su mando; este abuso del que se están siguiendo otros que continuamente me participan, a lo que debo ocurrir, como gobernador de esta capitanía, dando las providencias necesarias para evitar el desorden que va en ello, me persuaden a que

dicernimentos, e menos verossimilidade. [...] Se os espanhóis se tem aproveitado do tempo para explorar como se lhe imputa todo aquele País, por que não fazem os portugueses o mesmo tomando conhecimento de todos aqueles distritos, e fazendo ver a esta Corte, que não vivem como se acham, em uma profunda ociosidade [...] Isso é o que V.S deve responder ao Tenente Coronel Mardel, o qual vai dando provas, ainda que por diverso modo, de ser tão inábil para o Serviço [...], como foi o seu Predecesor". "Carta del Ministro de los Negocios Ultramarinos, Martinho de Mello e Castro, al Capitán General João Pereira Caldas. Nuestra Señora de la Ayuda, 26 de junio de 1783”, MA, APEP, caja 17, códice 1009, docs. 194-195.

${ }^{54}$ Reis, Lobo, 21-23. 
de acuerdo con Vuestra Señoría dictemos nuestras órdenes de manera que ambos nos conservemos en los límites que nos competen, sin excedernos en lo que se tiene permitido, pues así como Vuestra Señoría ciertamente no habría de consentir que mi gente entrando en la provincia de Mainas, gobierno de Vuestra Señoría, allí se condujese a mi arbitrio, sin dependencia de las órdenes y permiso de Vuestra Señoría, así también tengo todo el derecho a pretender que en esta capitanía de la que soy gobernador legítimamente, no tenga la partida de Vuestra Señoría más libertades que las que yo consienta.

En vista pues de todo eso, mando para Cupacá un teniente de infantería con algunos militares más para impedir que en aquel lugar, y sus vecindades, sin licencia mía no se levanten casas, ni se hagan rozas, ni se corten maderas de construcción de aquellos bosques, sino por las personas que fuesen propiamente moradores de esta capitanía y, en consecuencia, vasallos de Su Majestad Fidelísima $^{55}$.

La maniobria ejecutada surtió el efecto deseado. Sorprendido e indignado por las medidas portuguesas y previendo que a partir de éstas no habría más posibilidad de mantener o dar continuidad al dominio español en territorio portugués, D. Francisco Requeña se retiró de Ega, acompañado por una comitiva compuesta de trescientas cincuenta y cinco personas, regresando a Mainas:

En consecuencia de todo lo que Vuestra Señoría me dice en sus dos cartas de 21 de mayo próximo pasado, y viendo ya, lleno de una justa admiración, practicarse con la mayor violencia las determinaciones con que V.S. se halla, tengo resuelto retirarme de estos dominios de Su Majestad Fidelísima con la partida de

\footnotetext{
55 "O abuso que se tem feito de uma simples Licença que se deu para a Partida de V.S $S^{a}$ fazer um pouco de peixe, e mais nada; Cuja Licença foi, além de um puro obséquio de condescendência do Sr. João Pereira Caldas, e de Chermont para com V.S , o efeito dos sentimentos de hospitalidade com que sempre desejamos tratar a V.S ${ }^{\mathrm{a}}$, e toda a Partida do seu Mando; este abuso de que se estão seguindo outros que continuadamente se me estão participando, a que eu devo ocorrer, como Governador desta Capitania, dando as providências necessárias para evitar a desordem que vai nela, tudo me persuade a que de aordo com V.S a passemos as nossas ordens em termos que ambos nos conservemosnos Limites que nos compete sem excedernos o que se tiver permitido, pois assim como V.S $\mathrm{S}^{\mathrm{a}}$ certamente não havia consentir que a minha /Gente entrando na província de Mainas Governo de V.S ${ }^{\mathrm{a}}$ ali se conduzisse a meu arbítrio sem dependência das ordens e permissão de V.S ${ }^{\mathrm{a}}$. assim eu também tenho todo o diretio para pretender que nesta Capitanía de que eu sou Governador legitimamente não tenha nela a Partida de V.S ${ }^{\mathbf{a}}$ mais liberdades que as que eu lhe consentir.

Em vista pois de tudo isso, mando para Cupacá um Tenente de Infantaria com mais alguns Militares para embaraçar que naquele Lugar, e Suas Vizinhanças, sem licença minha se não erijam Casas se não façam roças, nem cortem Madeiras de construção daquelas Matas,senão as pessoas que forem popriamente Moradores desta Capitania,e por conseqüência Vassalo de S.Magestade Fidelíssimas". "Carta del Coronel Manoel da Gama Lobo d'Almada a D. Francisco Requeña. Barcelos, 21 de mayo de 1791”, citado por Reis, Lobo, 188-191.
} 
expedición de límites del Rey mi augusto amo, a mi gobernación de Mainas, territorios de la misma Majestad ${ }^{56}$.

Estaban definitivamente terminadas las demarcaciones de fronteras entre los dominios de Portugal y España en el Nuevo Mundo.

\section{Conclusión}

La noción de frontera en la Amazonía evolucionó a lo largo de tres siglos. Inicialmente, antes incluso del siglo XVII, el concepto de frontera formulado por el gobierno colonial portugués se basó en un conocimiento elemental de la red hidrográfica de la región. Por lo tanto, la frontera geográfica o también, la extensión territorial, no pasaba de ser una idea vaga, apenas una noción fluvial, o mejor dicho, una noción de frontera líquida.

La Amazonía brasileña comenzó a tener una historia de poblamiento y una historia de fronteras a partir del siglo XVII y, por la evolución del proceso histórico, nuevos conceptos fueron concebidos. En este periodo el concepto inicial evolucionó desde una noción fluvial hacia una noción de espacio territorial ampliado y de ahí hacia la formulación de un concepto de frontera humana, cuando Portugal tornó conciencia de la importancia de los indios amazónicos como aliados y como mano de obra indispensable, sobre todo en los trabajos de recolección de drogas del sertón y en la pesca.

En el siglo XVIII la percepción portuguesa de las potencialidades económicas ofrecidas por la región amazónica determinó la formación de otro concepto de frontera: la política. La transformación de la Amazonía en posesión territorial a través de la acción militar era la expresión de este concepto. A partir de esa nueva conceptualización, los portugueses emprendieron una gran ampliación de las fronteras territoriales a través de las conquistas militares, volviéndose comunes los conflictos armados con la población indígena de la región.

Son perceptibles las profundas y continuas reformulaciones del concepto portugués de frontera en un corto espacio de doscientos años. Éste evolucionó desde la idea geográfica de frontera física hasta el concepto de frontera humana y poco tiempo después hacia el concepto de frontera política: el derecho de posesión, confirmado por los tratados de Madrid en 1750 y de San Ildelfonso en 1777, cuando las Coronas ibéricas acordaron definir sus dominios en el sur de América.

Sin embargo, como se puede ver, una vez más fue comprobado que la frontera no puede ser determinada en gabinetes o palacios, sino en la realidad que se presenta en el día a día de su

\footnotetext{
56 “Carta de D. Francisco Requeña al Coronel Manoel da Gama Lobo d'Almada. Ega, 25 de junio de 1791”, citado por Reis, Lobo, 192-193.
} 
territorio: "La frontera es determinada no por la naturaleza, sino por el hombre y como el hombre se transforma, la frontera no puede ser rígida" ${ }^{57}$.

La Amazonía se mantuvo, a pesar del fracaso de la segunda tentativa de determinación de sus límites, y para ésta quedaban el reconocimiento de su región (descrito en mapas, informes, diarios y memoriales) y la lección de la diplomacia. Es también interesante destacar que los problemas ocurridos en el río Japurá, que ocasionaron la suspensión de las demarcaciones y posteriormente su cancelación definitiva, ofrecieron muchas más oportunidades de reconocimiento físico y poblacional de la región, y también la demarcación de los límites nacionales como los conocemos hoy, que si los trabajos hubieran transcurrido de acuerdo con lo firmado en el Tratado y hubiera tenido éxito la estrategia diseñada para el norte de la América portuguesa, en la segunda mitad del siglo XVIII.

\section{Bibliografía}

\section{Fuentes primarias}

Amoroso, Marta Rosa y Nádia Farage, comp. Relatos da Fronteira Amazônica no século XVIII: Documentos de Henrique João Wilckens e Alexandre Rodrigues Ferreira. São Paulo: NHII; USP, FAPESP, 1994.

"Demarcações no Alto Rio Negro-Cartas e Relatórios, 1783 a 1785". Livro Cedeam E025 AHU. Museu Amazônico, Universidade Federal de Amazonas.

Documentos Avulsos. Arquivo Público do Estado do Pará (APEP). Museu Amazônico, Universidade Federal de Amazonas.

Ferreira, Alexandre Rodrigues. Viagem Filosófica ao Rio Negro. Belém: MPEG, 1983.

"Limites do Brasil (1493 a 1851)". Revista Trimensal do Instituto Histórico, Geográfico e Etnográfico do Brasil. Tomo 30, parte segunda (s.f.): 193-240.

Souza, André Fernandes de. "Notícias Geográficas da Capitania do Rio Negro no Grande Rio das Amazonas". Revista Trimensal de História e Geografia e Etnográfico do Brasil. No. 12 (1848): 411-504.

\section{Fuentes secundarias}

Angel, Jacques. Géopolitique des Frontières. París, 1938.

Araújo e Amazonas, Lourenço da Silva. Dicionário Topográfico e Descriptivo da Comarca do Alto Amazonas. Recife: Typographia Commercial de Meira Henriques, 1852.

Barata, Carlos E. de Almeida y Antônio H. da Cunha Bueno. Dicionário das Famílias Brasileiras. Vol. 1. São Paulo: Iberoamérica, s.f.

\footnotetext{
${ }^{57}$ Jacques Angel, Géopolitique des Frontières (París: 1938), 48; citado por João Renor, "O avanço do povoamento para as fronteiras definitivas da Amazônia brasileira do periodo colonial aos nossos dias", Boletim de Pesquisa da CEDEAM 4, no. 6 (1985), 81.
} 
Beozzo, José Oscar. Leis e Regimentos das Missões: política indigenista no Brasil. São Paulo: Loyola, 1983.

Freitas, Aimberê. Fronteira Brasil/Venezuela: Encontros e Desencontros. São Paulo: Corprint Gráfica e Editora, 1998.

Giraldo, Manuel L. Francisco de Requeña y otros: Ilustrados y bárbaros - Diario de la exploración de límites al Amazonas (1782). Madrid: Alianza Editorial, 1991.

Queiroz, Jonas Marçal de y Mauro C. Coelho. Amazônia: Modernização e Conflito (séculos XVIII e XIX). Belém: UEPA/NAEA, 2001.

Reis, Arthur C. Ferreira. História do Amazonas. 3a. ed. Belo Horizonte: Itatiaia, 1998.

Limites e Demarcações na Amazônia Brasileira-A Fronteira com as Colônias Espanholas. Vol. 2. Coleção Lendo o Pará, no. 15. Belém: SECULT, 1993. Lobo d'Almada: um estadista colonial. Manuscrito, 1940.

Renor, João. "O avanço do povoamento para as fronteiras definitivas da Amazônia brasileira do periodo colonial aos nossos dias". Boletim de Pesquisa da CEDEAM 4, no. 6 (1985): 73-91.

Varnhagem, Francisco Adolpho. História Geral do Brasil: antes de sua aeparação e independência de Portugal. Tomos 3 y 4. 10a. ed. São Paulo: EDUSP, 1981.

\section{Fuentes electrónicas}

http://www.institutopaubrasil.org.br/personal.htm.

Fecha de recepción del artículo: 31 de marzo de 2003

Fecha de aceptación: 22 de agosto de 2003 


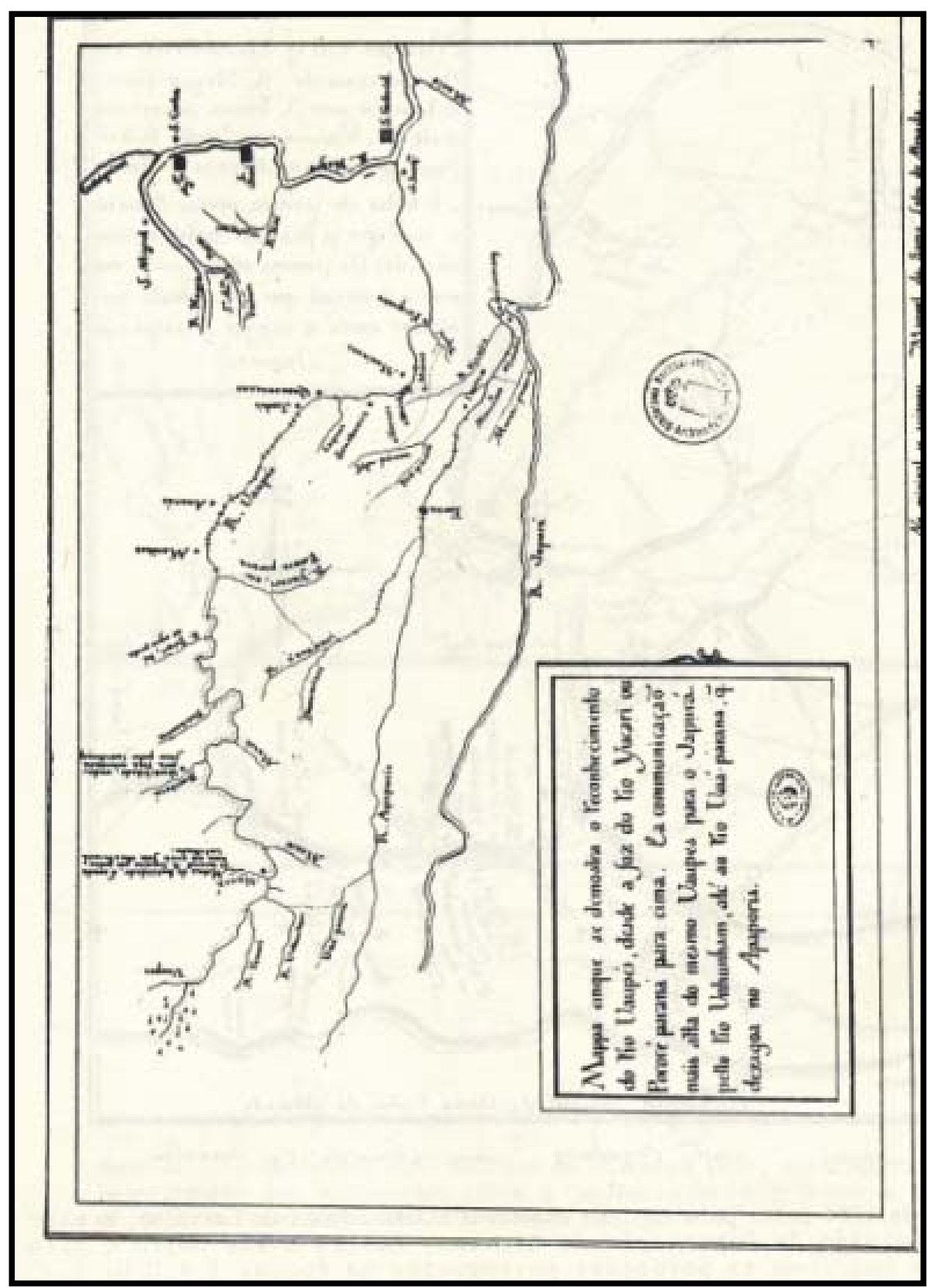

Fig. 6. Mapa de las posesiones portuguesas en el norte del Brasil a finales del siglo XVIII. Elaborado en 1798 por el capitán Antonio Joaquim Simões. Tomado de: Boletim de CEDEAM, $\mathrm{n}^{\circ} 6$ (Manaus: Universidade do Amazonas, 1985) 